\title{
Structure-Gas Transport Property Relationships of Poly(dimethylsiloxane-urethane) Nanocomposite Membranes
}

\author{
Boreddy S. R. Reddy and D. Gnanasekaran \\ Industrial Chemistry Laboratory, Central Leather Research Institute (Council of Scientific \\ $\mathcal{E}$ Industrial Research), Chennai-600 020
}

India

\section{Introduction}

Hybrid organic-inorganic materials based on incorporation of polyoctahedral oligomeric silsesquioxanes (POSS) into polymeric matrices have received a considerable attention (Gnanasekaran et al, 2009; Krishnan et al, 2005; Chang et al, 2003; Phillips et al, 2004; Kudo et al, 2006; Hong, 1997; Isayev et al, 2004; Ni et al, 2004). Silsesquioxane (Fig. 1) (Laine et al, 2005) consists of a rigid, crystalline and silica-like core structure.

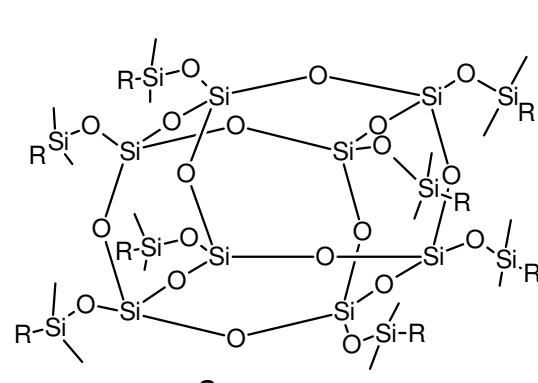

a

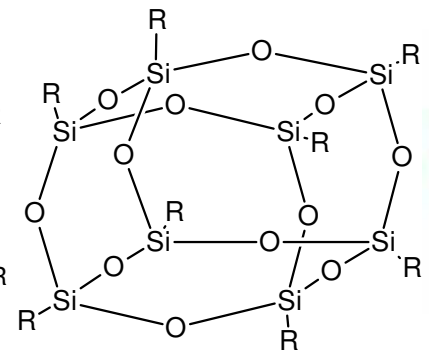

b

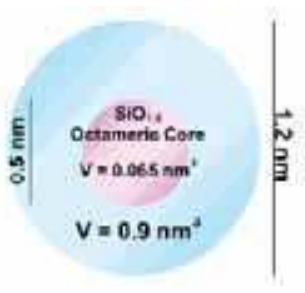

C

Fig. 1. Silsesquioxanes. (a) $\mathrm{Q} 8\left(\mathrm{Q}=\mathrm{SiO}_{2 / 2}\right) ; \mathrm{R}=\mathrm{H}$, vinyl, epoxy, methacrylate, etc. (b) $\mathrm{R}_{8} \mathrm{~T}_{8}\left(\mathrm{~T}=\mathrm{R}-\mathrm{SiO}_{3 / 2}\right) ; \mathrm{R}=$ alkyl, alkene, acetylene, acrylate, (c) Typical sizes/volumes.

POSS derivatives have two unique features: 1$)$ Their chemical composition $\left(\mathrm{RSiO}_{1.5}\right)$ was found to be intermediate between that of silica $\left(\mathrm{SiO}_{2}\right)$ and siloxane $\left(\mathrm{R}_{2} \mathrm{SiO}\right)$. 2) POSS compounds can be tailored to have various functional groups or solubilizing substituents that can be attached to the POSS skeleton. POSS molecule was perfectly defined spatially $(0.5-0.7 \mathrm{~nm})$, have general formula $\left(\mathrm{RSiO}_{1.5}\right)_{a}\left(\mathrm{H}_{2} \mathrm{O}\right)_{0.5 b}$, where $\mathrm{R}$ is a hydrogen atom or an organic group and $a$ and $b$ are integer numbers $(a=1,2,3, \ldots ; b=0,1,2,3, \ldots)$, with $a+b=$ $2 n$, where $n$ is an integer $(n=1,2,3, \ldots)$ and $b \leq a+2$. Of several structures of silsesquioxanes (random, ladder and cage), cage structure contains 8 silicon atoms placed at cube vertices. Cubic structural compounds (completely and incompletely condensed silsesquioxanes) are commonly illustrated as $\mathrm{T}_{6}, \mathrm{~T}_{7}, \mathrm{~T}_{8}, \mathrm{~T}_{10}$ and $\mathrm{T}_{12}$ based on the number of silicon atoms present 
in cubic structure (Fig. 2). POSS based compounds were thermally and chemically more stable than siloxanes. A variety of POSS nanostructured chemicals contain one or more covalently bonded reactive functionalities that are suitable for polymerization, grafting, surface bonding, or other transformations (Lichtenhan et al, 1999; Lichtenhan et al, 2001). Incorporation of nanosized POSS macromers into polymers have produced significant property enhancements in processability, toughness, thermal and oxidative resistance as well as reduction in flammability and increased gas permeability.
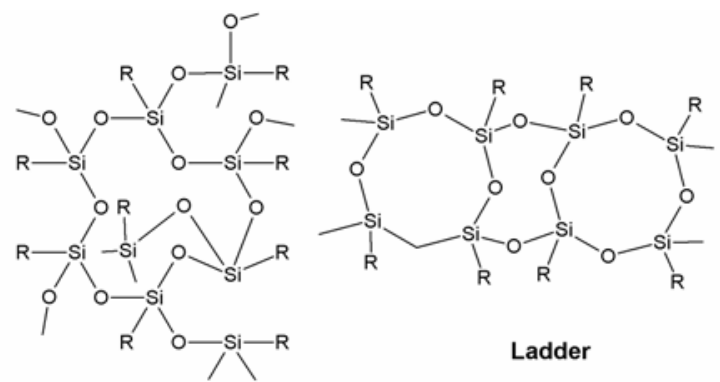

Ladder
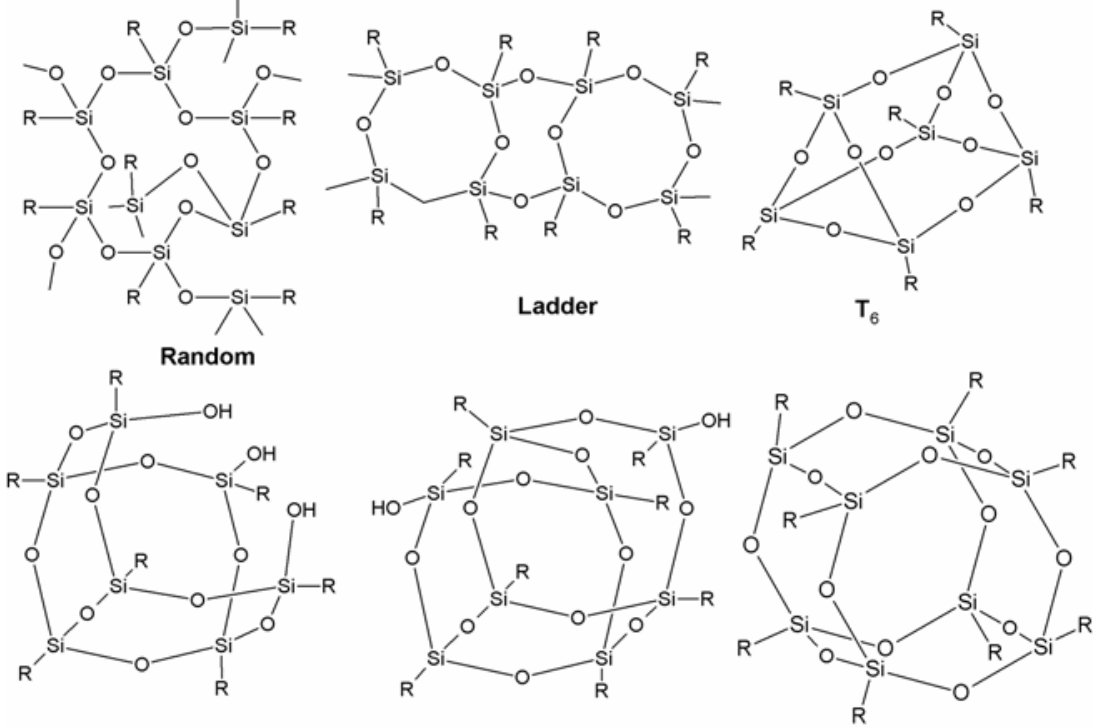

$\mathbf{T}_{7} \mathbf{a}$

$\mathbf{T}_{7} \mathbf{b}$

$\mathbf{T}_{8}$

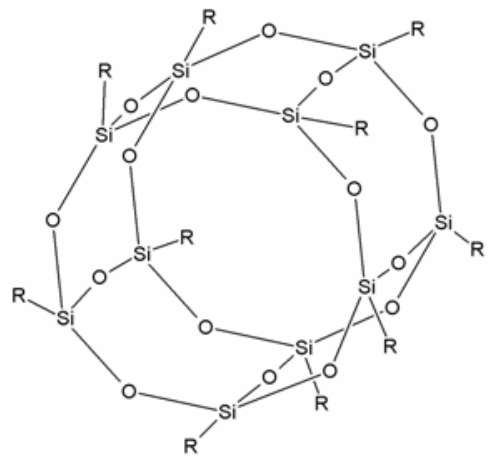

$\mathbf{T}_{10}$

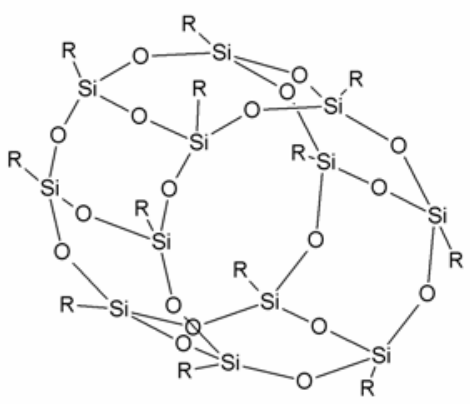

$\mathbf{T}_{12}$

Fig. 2. Chemical Structures of different types of silsesquioxanes

\subsection{Classification of silsesquioxanes}

The chemistry of silsesquioxanes were classified into three broad groups on the basis of functional groups 


\subsubsection{Mono-functional silsesquioxanes:}

These are suitable POSS monomers for the synthesis of linear thermoplastic nanocomopsites. Prepared by the selective hydrolysis of alkyl or aromatic trichlorosilane with water followed by in situ reaction with $\mathrm{R}^{\prime} \mathrm{SiCl}_{3}\left(\mathrm{R}^{\prime}=\right.$ functional group). Corner capping reaction yields a closed cube with 7 corners of inert groups (cyclopentyl or cyclohexyl) and the remaining one vertex possesses highly reactive functional group such as amine (Haddad and Lichtenhan, 1996), styryl (Ikeda and Saito, 2007) acrylic (Zhang, 2009), epoxide (Liu and Zheng, 2006), norbornyl (Zheng et al, 2001) and bisphenol (Iyer and Schiraldi, 2007) (Fig. 3).

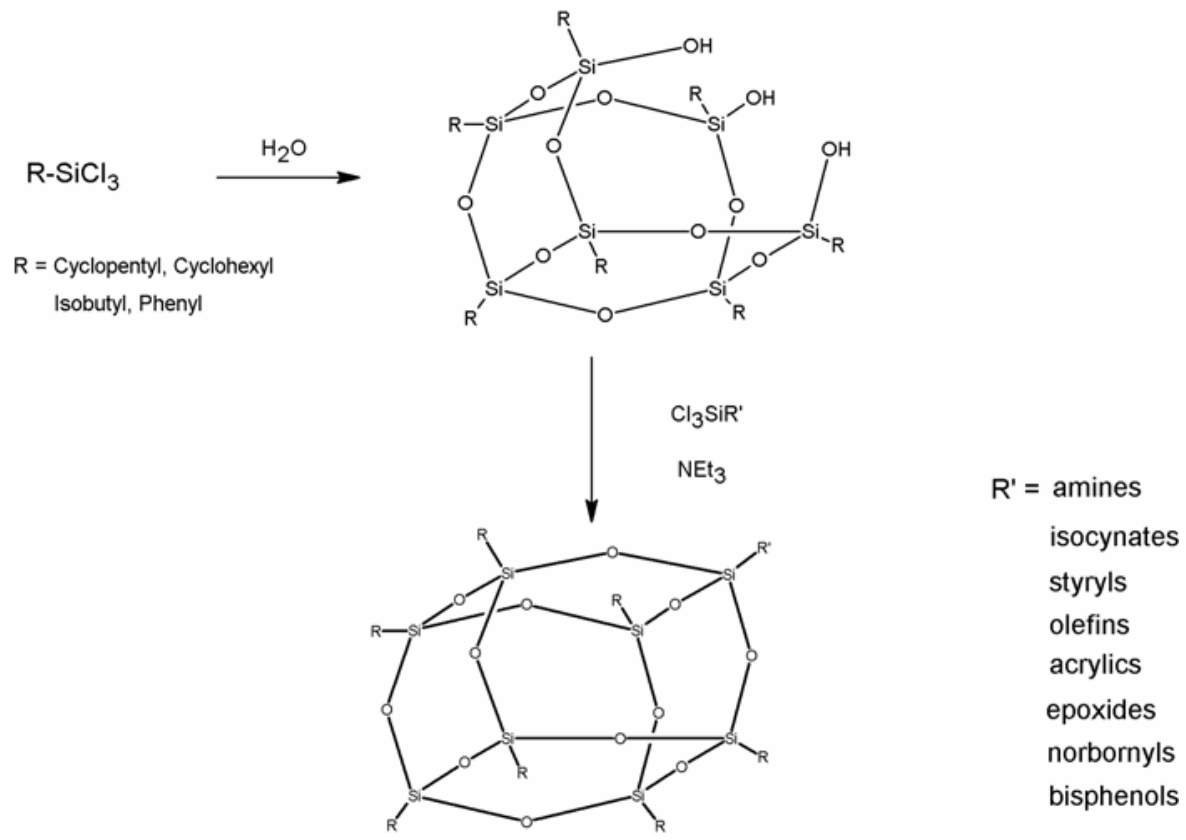

Fig. 3. Synthesis and structures of monofunctional POSS macromonomers

\subsubsection{Multifunctional monomers}

These are prepared by hydrosilylation reaction using Pt catalyst with either $m$-isopropenyl$\alpha$ - $\alpha$-dimethylbenzyl isocyanate or 2-chloroethyl vinylether or allyl alcohol or 4acetoxystyrene or 4-[(2-(vinyloxy)ethoxy)methyl]cyclohex-1-ene (Fig. 4). 

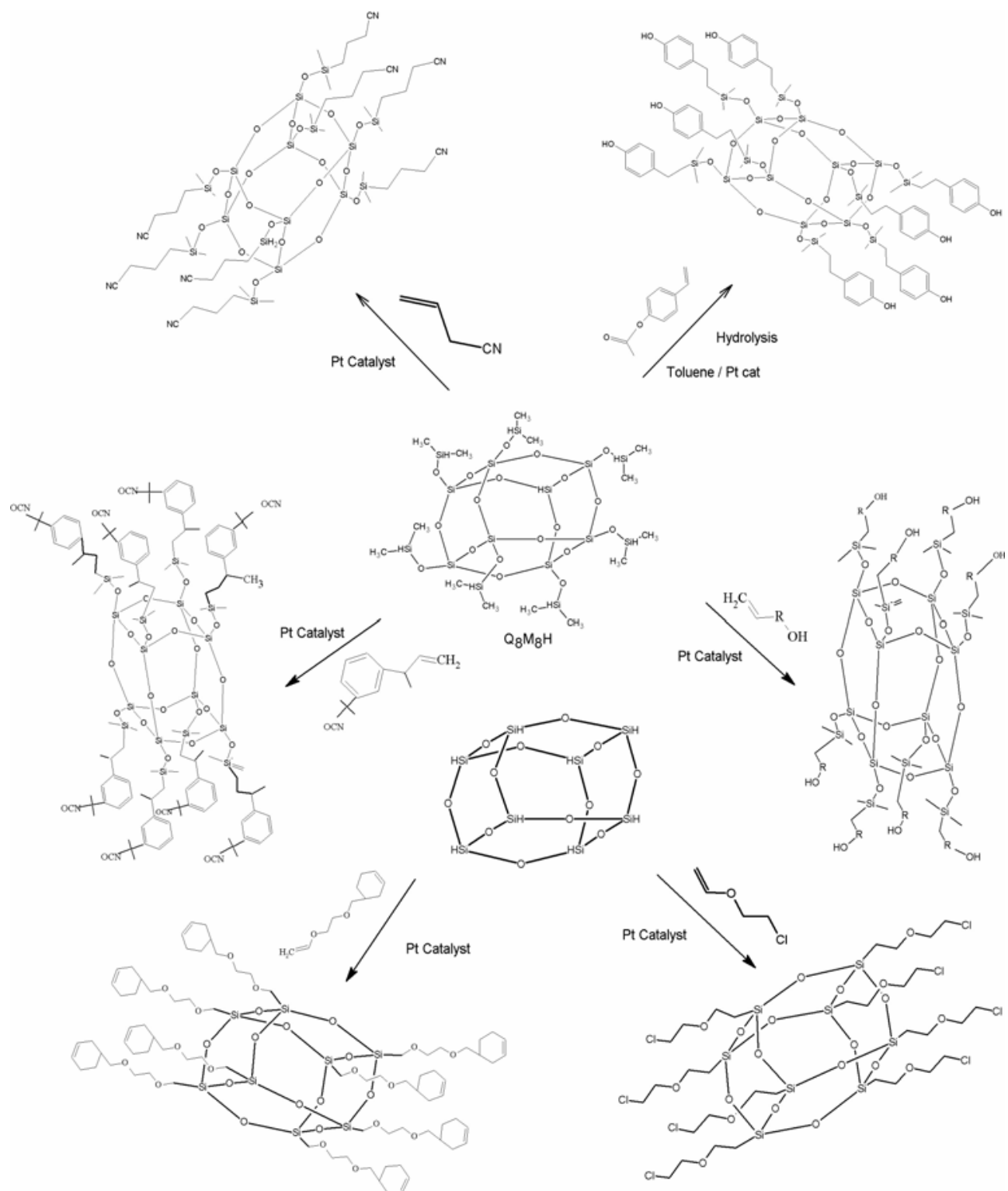

Fig. 4. Synthesis of octafunctional POSS macromonomers through hydrosilylation reaction

\subsubsection{Incomplete silsesquioxanes}

Heptameric siloxanes with partially formed cages containing 2 or 3 residual silicon hydroxyl functional groups, obtained through hydrolysis/condensation of alkyl- or aryl trichlorosilanes, are called as incomplete silsesquioxanes. A variety of NCs were obtained through reactive silicon hydroxyl functional groups(-SiOH) (Fig. 5). 


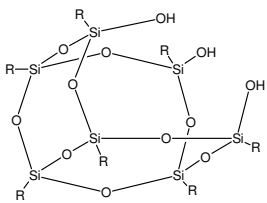

$\mathrm{R}=$ Cyclopentyl or Cyclohexyl or Phenyl
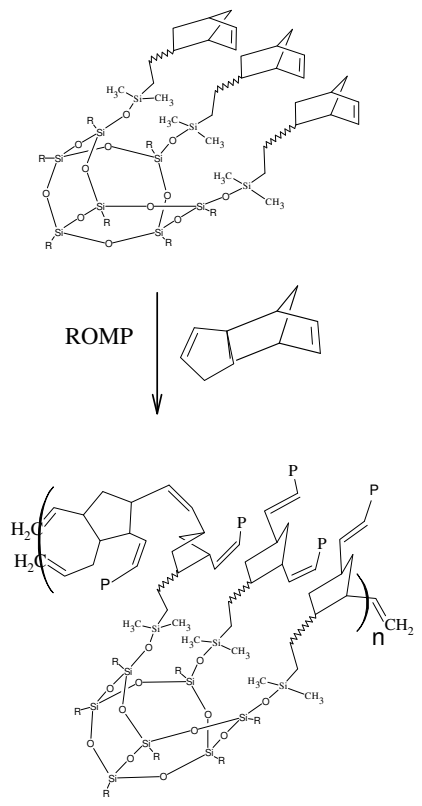

Polynorbornene
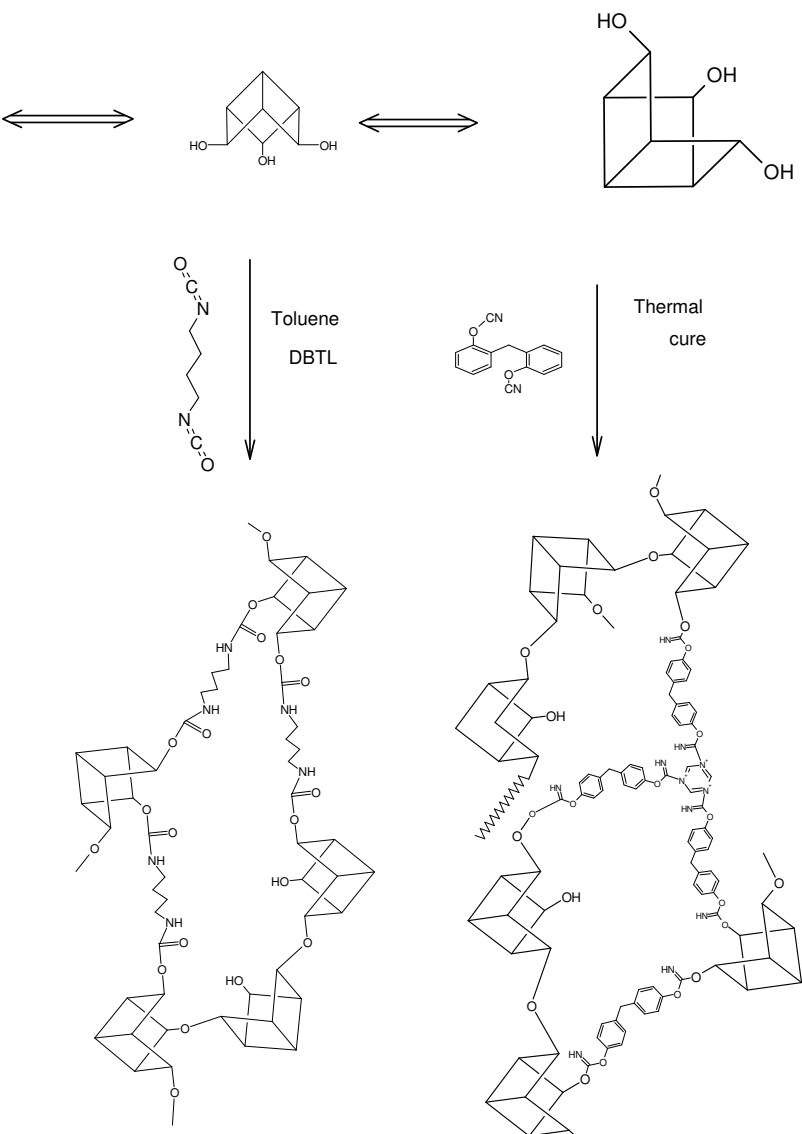

Polyurethane
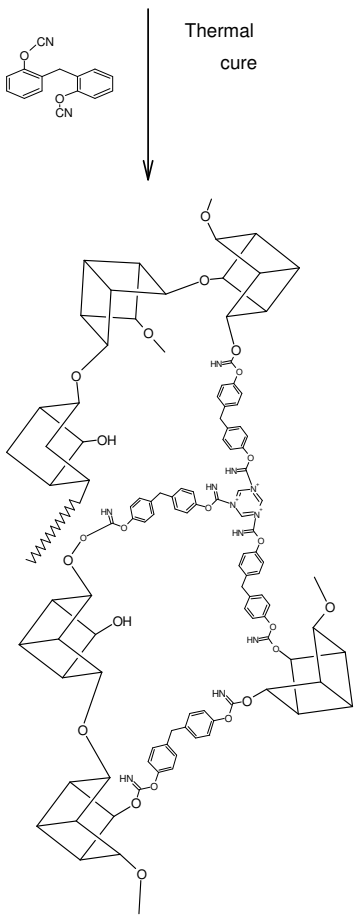

Cyanate ester

Fig. 5. Synthesis of polynorbornene, polyurethane and cyanate ester nanocomposites using partially caged silsesquioxanes.

\subsection{Preparation of membranes - literature reports}

Organic-inorganic hybrid membranes could be prepared by simply embedding the inorganic particles such as silica, $\mathrm{TiO}_{2}, \mathrm{ZrO}_{2}$ alumina, and carbon molecular sieves (Peinemann et al, 2005; Yave et al, 2007; Genne et al, 1997; Wara, 1995; Miller, 2003). In particular the incorporation of nanosized inorganic particles in the membranes is of more interesting in the gas separations. The main disadvantage of incorporating fillers to the polymers by blending is the agglomeration of particles and formation of nonselective voids at the interface of particles and the polymer matrix. The formation of voids between both materials could be controlled through in situ generation of inorganic nanoparticles in the polymer matrix through sol-gel process or crosslinking the functional group of nanoparticle with polymer functional groups (Nunes, 1999; Park, 2003). Therefore, the modification of 
fillers and matrices has become an expanding field of research as the introduction of functional groups can improve dispersion of fillers and change chemical affinities of penetrants in nanocomposite membranes. There is much scope for research innovation and the development of polymer-inorganic nanocomposite membranes for gas separation.

\subsection{Importance of membrane technology}

Natural gas plays an important role in today's energy production and is one of the fastest growing fossil fuels. It has been widely used as the energy source for electricity generation as well as the natural gas powered vehicles domestic appliances, manufacturing of metals and chemicals. According to the available statistics that US produces $50 \%$ of this domestic comsumption of electricity through the combustion of natural gas. There is energy possibility that the dramatic increase use of natural gas in the next 20-30 years. This main reason being that the natural gas offers many environmentally friendly properties without producing sulphur oxides (SOx), low levels of nitrogen oxides (NOx) and relatively lower emissions of carbon dioxide than those of other fossil fuels such as coal and oil. $\mathrm{CO}_{2}$ is a major component contributing to the sweetening of natural gas and causing greenhouse effect. Therefore, the separation of $\mathrm{CO}_{2}$ from natural gas is utmost important as this may dramatically reduce the pipeline corrosions and enhance the efficiency of high-purity energy products (Paul and Yampol'skii, 1994; Table-Mohammadi, 1999; Li et al, 2007). According to acceptable pipeline requirements for optimizing corrosion, the concentration specification of $\mathrm{CO}_{2}$ must be $<2 \%$. Amine absorption is a main strategy that is currently employed in the industry to facilitate $\mathrm{CO}_{2}$ removal from natural gas (Yeh and Pennline, 2001). In contrast, membrane separation processes have been proven to be technically and economically far superior in view of their versatile properties, simplicity and ease of installation and operation, low maintenance requirements and reduced cost.

\subsection{Structure - property relationships}

\subsubsection{Morphology effect on permeability:}

Generally, surface morphology of memebranes depend on polymer molecular structure, composition, molecular weight, and can also be influenced by a suitable choice of the substrate surface free energy. The POSS portion combines the features of organosilicon compounds and possess low free energy (Youngblood and McCarthy, 1999). Thus, the enrichment of the POSS portion at the surface could occur upon incorporating the organicinorganic amphiphile into organic polymer and the surface hydrophobicity of materials will significantly be enhanced (Koh, 2005). Hence, the hydrophobic part of POSS was chosen to study the effect of POSS on surface morphology of polymers and thereby influencing the permeability and selectivity of gases.

\subsubsection{Incorporation of PU/PI on mechanical properties of PDMS:}

Polydimethylsiloxane (PDMS) $\left(\bar{M}_{n}=5,600\right)$ has the highest gas permeability of all synthetic polymers produced so far on an industrial scale, except for some glassy polymers with a high free volume fraction. However, it has poor separation ability for small gas molecules (eg., $\mathrm{O}_{2}, \mathrm{~N}_{2}, \mathrm{H}_{2}$ and $\mathrm{CO}_{2}$ ), and low mechanical properties that restrict its application in gas separation (Achalpurkar et al, 2007; Sheth, 2004). On the other hand, polyurethanes and polyimides are promising materials that have good mechanical properties and better gas selectivities (Huang and Lai, 1995; Yoshino et al, 2000; Yang et al, 2002). In our previous 
work, we have reported that the PDMS based polyurethanes show better gas separation process (Madhavan and Reddy, 2006). However, it was observed that increase in PDMS content was associated with a decrease in the mechanical properties and gas selectivities. In order to retain both selectivity and permeability with good thermal and mechanical properties, we have incorporated POSS nanoparticles in the hybrid membranes by chemically reacting functional groups of POSS molecules with the polymer matrices. Here, we have tried to optimize the adopted synthetic strategy to obtain hybrid materials suitable for membrane preparation and expect to have better separation factor for gas mixtures.

\subsubsection{Effect of PDMS on thermal properties of PU:}

There are many accepted approaches for the improvement of thermal stability of PUs. One of the important approaches is the chemical modification of its structure by blending or copolymerizing with more thermally stable polymers such as PDMS (Wang et al, 2000) or polyimide (PI) (Yeganeh and Shamekhi, 2004). However, the incorporation of PDMS leads to a decrease in the mechanical properties, whereas PI imparts poor solubility. Also, the difficulty in processing techniques limits the usage of PI and PDMS in PUs. The other way of solving this problem is to modify the thermal and mechanical properties of PU by blending nanoparticles into the thin films of diblock copolymers of PU using $\mathrm{ZnO}$ nanoparticle. However, the nanoparticles having controlled and well-defined surfaces are needed to control the properties of block copolymers (Zheng et al, 2005). We have developed a synthetic strategy to link up POSS based nanoparticles covalently rather than blending or doping. This methodology stops leaching out of the nanoparticles from the membrane and provides longer life for the usage of membranes.

A very few research works were reported on PU's incorporated POSS macromer because functionalization of POSS macromer to form PU nanocomposite is difficult. Neumann et al (2002) synthesized PU network using isocyanate-functionalized POSS cage and polyethylene glycol. Liu and Zheng (2005) and Liu et al (2006) used amine- and hydroxylfunctionalized POSS cages for the synthesis of PU-POSS nanocomposite. Fu et al. (2001) synthesized POSS group pendant to PU chain. Recently, Oaten and Choudhury (2005) synthesized a POSS-urethane hybrid using isobutyltrisilanol POSS with hexamethylene diisocyanate (HMDI) and they have shown that the POSS incorporation improves the thermal and mechanical stability of thin PU hybrid films. Liu et al (2005) obtained polyurethane networks with POSS by reacting octa(amino)phenylsilsesquioxane with isocyanate terminated polyurethane prepolymer. Thermal stability of hybrid polyurethanes is more than conventional PU elastomer due to nanoscale reinforcement effect of POSS on polyurethane networks.

\section{Synthesis of macromers and polymers}

The experimental details about the synthesis of allyl-4-nitrobenzoate, synthesis of allyl 4aminobenzoate and the synthesis of POSS-amine were reported by us earlier (Madhavan and B. S. R. Reddy, 2009).

Synthesis of octakis(hydridodimethylsiloxy)octasilsesquioxane (Completely condencedPOSS) (POSS-H) and the synthesis of heptacyclopentyl tricycloheptasiloxane triol (Incompletely condenced-POSS) (CyPOSS) were reported elsewhere (Madhavan et al, 2009). The experimental details about the synthesis of N-(POSS)-7-oxanorbornene-5, 6-dicarboximide (NPONDI) were reported by us earlier (Gnanasekaran and B. S. R. Reddy, 2010). 


\subsection{POSS-PDMS and POSS-PPG membrane preparation}

Into a $100 \mathrm{ml}$ three necked flask, methylene diphenyl diisocyanate (MDI) dissolved in $10 \mathrm{ml}$ of dry THF was added under nitrogen atmosphere. To this, pre-determined amount of PDMS and/or polypropylene glycol (PPG) $\left(\mathrm{M}_{\mathrm{n}}=3,500\right)$ and POSS-amine (Table 1) dissolved in $20 \mathrm{ml}$ of THF was added at $60^{\circ} \mathrm{C}$. Then 1-2 drops of DBTDL catalyst was added and stirred the reaction mixture vigorously for $6 \mathrm{~h}$ (Sheme 2). Finally, the reaction mixture was poured into teflon coated glass plate and kept for curing at room temperature. To prevent dust pollution, the glass plate was covered with a filter paper. The hybrid film was then peeled out from the glass plate and dried at $80^{\circ} \mathrm{C}$ in the atmospheric air for $48 \mathrm{~h}$.

A schematic representation of the membrane formation was given in the schemes 1 and 2 .<smiles>C=CCOC(=O)c1ccc(N)cc1</smiles>
Hydrosilylation $\downarrow \begin{aligned} & \text { Pt(dvs) } \\ & \text { Toluene }\end{aligned}$

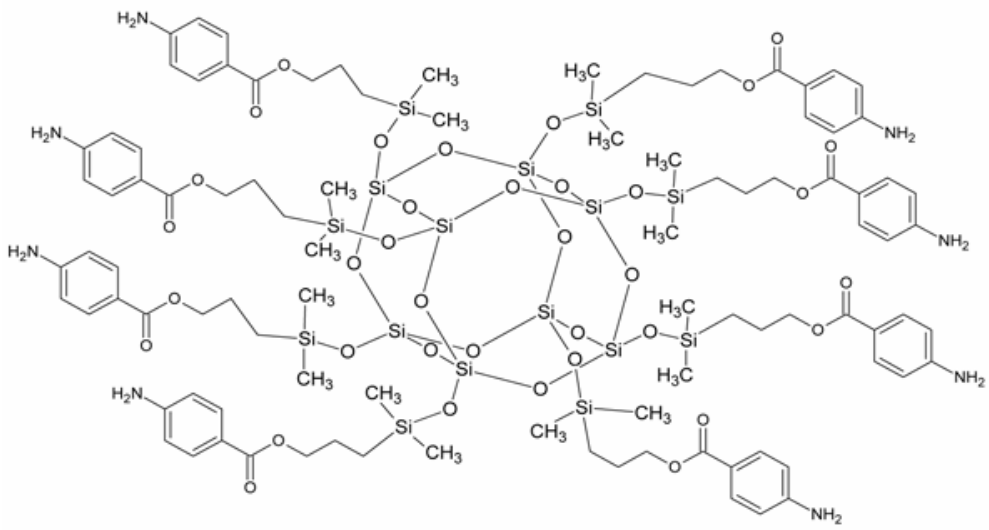

POSS-amine

Scheme 1. Synthesis of POSS-amine 

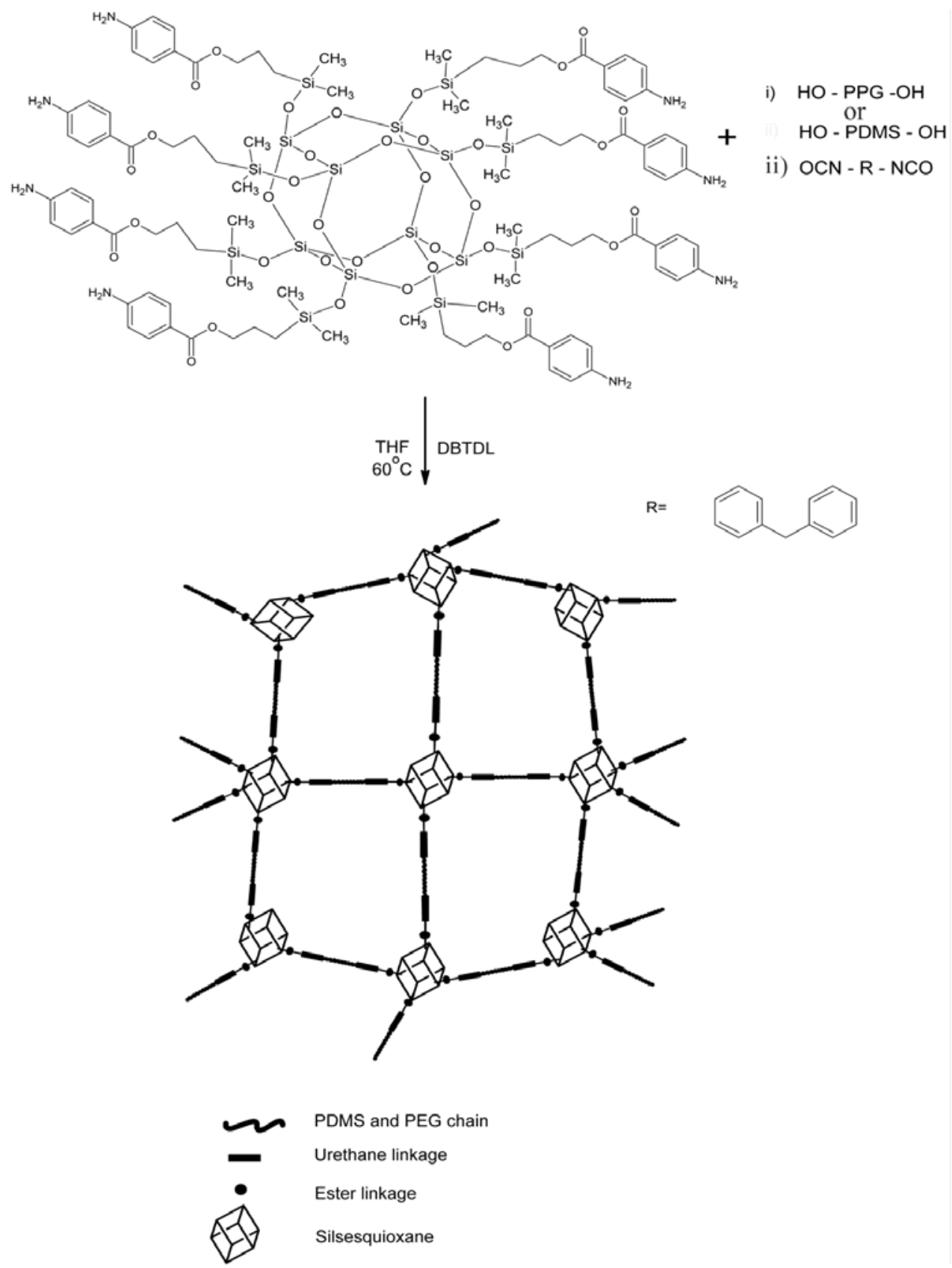

Scheme 2. Synthesis of POSS-PDMS and POSS-PPG hybrid nanocomposites 


\subsection{Synthesis of PU-POSS hybrid nanocomposites}

Into a 100ml three neck flask, hexamethylene diisocyanate (HMDI) was dissolved in $10 \mathrm{ml}$ of dry toluene under nitrogen atmosphere. To this, predetermined amount of PDMS, CyPOSS and POSS-H (Table 1) dissolved in $20 \mathrm{ml}$ of toluene was added at $60^{\circ} \mathrm{C}$. Then $1-2$ drops of dibutyltin dilaurate (DBTDL) catalyst was added and the reaction mixture was stirred vigorously for $6 \mathrm{~h}$. The rest of the procedure was adopted as given under POSS-PDMS and POSS-PPG membrane preparation.

A schematic representation of the membrane formation was given in the schemes 3 and 4 .

\begin{tabular}{|c|c|c|c|c|c|c|c|c|}
\hline S.No & Sample & $\begin{array}{c}\text { PDMS } \\
(\mathbf{w t} \text { ) }\end{array}$ & $\begin{array}{c}\text { HMDI } \\
(\mathbf{w t} \text { ) }\end{array}$ & $\begin{array}{c}\text { CyPOSS } \\
(\mathbf{w t} \text { ) })\end{array}$ & $\begin{array}{c}\text { POSS-H } \\
(\mathbf{w t} \%)\end{array}$ & MDI & PPG & $\begin{array}{c}\text { POSS- } \\
\text { amine }\end{array}$ \\
\hline $\mathbf{1}$ & PU-POSS-1 & 70 & 20 & 10 & - & - & - & - \\
\hline $\mathbf{2}$ & PU-POSS-2 & 70 & 17.5 & 10 & 2.5 & - & - & - \\
\hline $\mathbf{3}$ & PU-POSS-3 & 70 & 15 & 10 & 5 & - & - & - \\
\hline $\mathbf{4}$ & PU-POSS-4 & 70 & 12.5 & 10 & 7.5 & - & - & \\
\hline $\mathbf{5}$ & POSS-PDMS-5 & 75 & - & - & - & 20 & - & 5 \\
\hline $\mathbf{6}$ & POSS-PDMS-15 & 65 & - & - & - & 20 & - & 15 \\
\hline $\mathbf{7}$ & POSS-PDMS-25 & 55 & - & - & - & 20 & - & 25 \\
\hline $\mathbf{8}$ & POSS-PPG-5 & 37.5 & - & - & - & 20 & 37.5 & 5 \\
\hline $\mathbf{9}$ & POSS-PPG-15 & 32.5 & - & - & - & 20 & 32.5 & 15 \\
\hline $\mathbf{1 0}$ & POSS-PPG-25 & 27.5 & - & - & - & 20 & 27.5 & 25 \\
\hline
\end{tabular}

Table 1. Various chemical compositions of PU-POSS, POSS-PDMS and POSS-PPG hybrid nanocomposites.

(I)

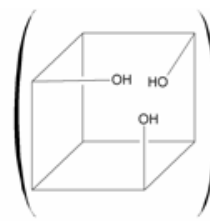

(II)

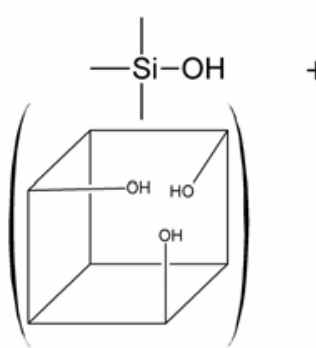

(III)

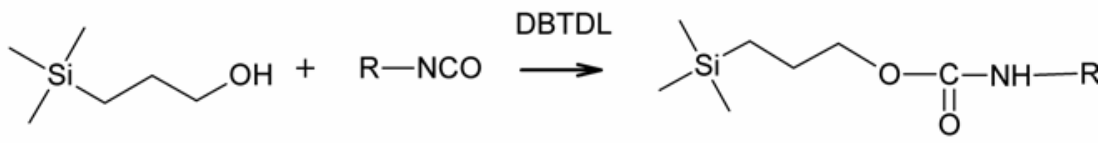

DBTDL-Dibutyltindilaurate<smiles>[R]NC(=O)O[Si](C)(C)[C@@H]([B])C</smiles><smiles>C[Si](C)(C)O[Si](C)(C)[18F]</smiles>

Scheme 3. Model reaction of the monomerfunctional groups 

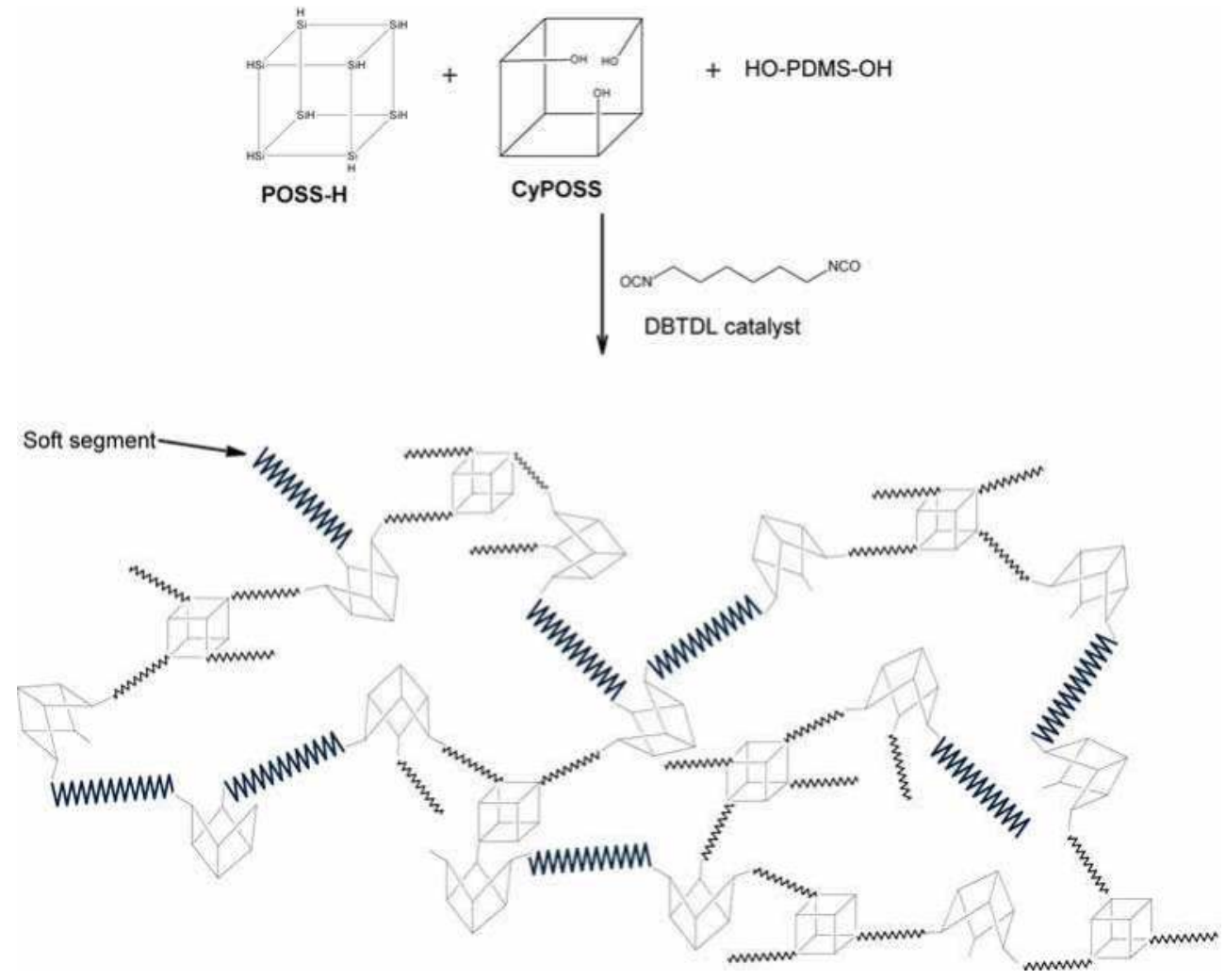

Scheme 4. Chemical structure of PU-POSS hybrids

\subsection{Synthesis of homo- and copolymers TFONDI and POSS-ONDI}

Ruthenium catalyst $1 \mathrm{mg}(0.0011 \mathrm{mmol})$ dissolved in $\mathrm{CHCl}_{3}$ was added to the solution of various compositions of TFONDI and POSS-ONDI macromonomer in chloroform (Table 2). The polymers were precipitated into $100 \mathrm{~mL}$ of methanol (yield $80 \%$ ).

\begin{tabular}{|c|c|c|c|c|c|c|c|}
\hline & TFONDI & $\begin{array}{c}\text { POSS- } \\
\text { ONDI }\end{array}$ & Mn X 10 & PDI & DSC & \multicolumn{2}{|c|}{ TGA } \\
\hline Sample & $\mathbf{( w t \% )}$ & $\mathbf{( w t \% )}$ & $\mathbf{( g / m o l )}$ & & Tg $\left({ }^{\circ} \mathbf{C}\right)$ & $\mathbf{T}_{5}{ }^{*}\left({ }^{\circ} \mathbf{C}\right)$ & $\begin{array}{c}\mathbf{T}_{50}{ }^{*} \\
\left({ }^{\circ} \mathbf{C}\right)\end{array}$ \\
\hline $\begin{array}{c}\text { Homopoly } \\
\text { (TFONDI) }\end{array}$ & 100 & - & 26.65 & 3.5 & 175 & 356 & 413 \\
\hline POSS25-ONDI & 75 & 25 & 20.37 & 1.7 & 180 & 336 & 409 \\
\hline POSS50-ONDI & 50 & 50 & 5.02 & 1.4 & 176 & 318 & 398 \\
\hline POSS75-ONDI & 25 & 75 & 4.28 & 1.3 & 173 & 320 & 385 \\
\hline
\end{tabular}

${ }^{*} \mathrm{~T}_{5}$ and $\mathrm{T}_{50}$ represents the decomposition temperatures at 5 and $50-\%$ weight loss

Table 2. Molecular weight, feed composition and thermal properties of homopoly(TFONDI) and copoly(POSS-ONDI-TFONDI) nanocomposites 


\section{Results and discussion}

\subsection{Synthesis and characterization of POSS-amine macromer}

In order to synthesize POSS incorporated hybrid materials, the functionalisation of POSS molecule is essential. To incorporate the functional group into the POSS molecule, hydrosilylation reaction is the best method to introduce the functional group with POSS molecule. Allyl-4-aminobenzoate was introduced into POSS $\left(\mathrm{Q}_{8} \mathrm{M}_{8} \mathrm{H}\right)$ molecule (Scheme 1) through hydrosilylation reaction using $\mathrm{Pt}(\mathrm{dvs})$ catalyst in toluene medium. The macromer synthesized was confirmed well with FT-IR and ${ }^{1} \mathrm{H}$ NMR. The characteristic Si-H band at $2100 \mathrm{~cm}^{-1}$ and the chemical shift at $4.7 \mathrm{ppm}$ which was fully disappeared confirming complete substitution in the POSS molecule. The POSS functionalised macromer was further characterized using ${ }^{29} \mathrm{Si}$ NMR spectroscopic technique. Figure 6 shows two chemical shift values corresponding to the two types of silicon atoms present in the macromer. The chemical shift at $13.6 \mathrm{ppm}$ corresponds to the silicon atom present at the outer core bonded to the POSS cube and a shift at $-108.52 \mathrm{ppm}$ was due to the silicon atom present in the core. The presence of these two chemical shifts confirm the complete substitution in the POSS molecule, which further supports that the cube structure of POSS has remained unaltered during the hydrosilylation reaction.

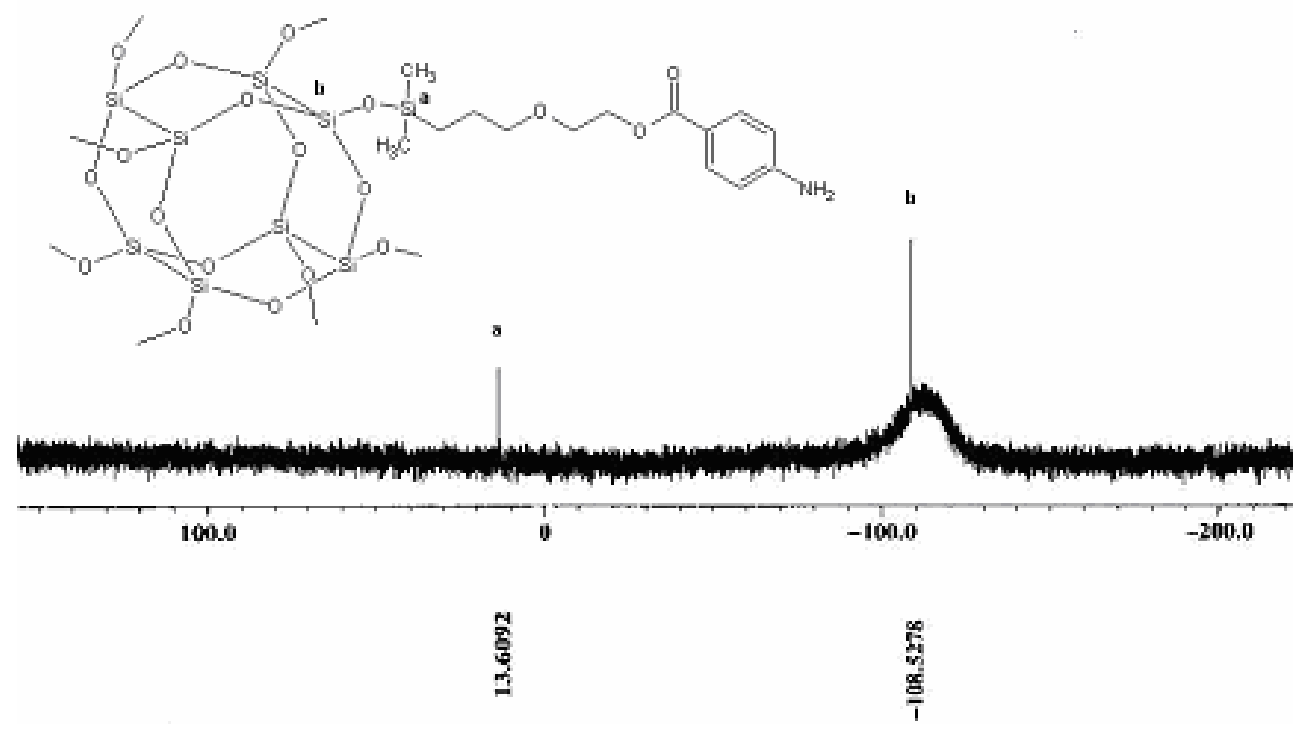

Fig. 6. ${ }^{29} \mathrm{Si}$ NMR of POSS-amine

\subsection{Synthesis of POSS-PDMS and POSS-PPG hybrid membranes}

Several compositions of POSS-amine incorporated membranes were synthesized and their chemical compositions were shown in Table 1. The POSS incorporated hybrids were characterized using ${ }^{29} \mathrm{Si} \mathrm{CP}-\mathrm{MAS}$ solid state NMR spectroscopic technique. ${ }^{29} \mathrm{Si}-\mathrm{NMR}$ spectrum of the POSS-PDMS-25 hybrid membrane was shown in Fig.7. The spectrum shows three chemical shift values corresponding to three types of silicon atoms present in the membrane. The chemical shift at $14.6 \mathrm{ppm}$ corresponds to the silicon atom (b) present in the outer core bonded to the POSS cube. The shift at -110.23 ppm was due to the silicon 
atom (a) present in the inner core. The chemical shift at -25 ppm was due to the silicon atom (c) of linear siloxane chain of membrane matrix. These chemical shifts were very close to the reported values by Sellinger et al (2007). The presence of chemical shifts at $14.6 \mathrm{ppm}$ and 110.23 ppm confirms the cubic structure of the POSS molecule which was unaltered during the formation of hybrid membrane.

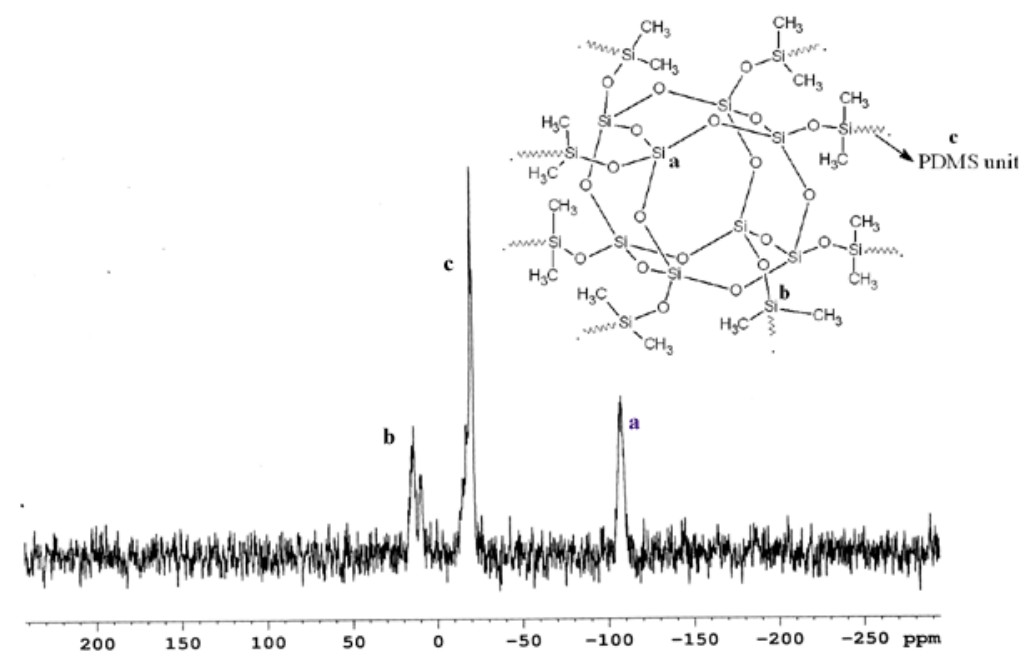

Fig. 7. ${ }^{29} \mathrm{Si}$ CP-MAS solid state NMR spectroscopic of POSS-PDMS and POSS-PPG membrane hybrids

\subsection{Synthesis of homo- and co-polymers of TFONDI and POSS-ONDI}

Phenyl-capped silsesquioxane POSS-Ph, POSS-Ph-NO $\mathrm{NO}_{2}$ POSS-Ph-NH $\mathrm{H}_{2}$ and N-(POSS)-7oxanorbornene-5,6-dicarboximide were reported by us earlier (Gnanasekaran and B. S. R. Reddy, 2010).

The homopolymer of TFONDI and the copolymers of TFONDI and POSS-ONDI have been prepared using the Grubbs ring opening metathesis polymerization (ROMP) catalyst. Attempts to prepare the homopolymer of POSS-ONDI was not successful, presumably due to the steric hindrance imposed by the bulky POSS group. The ${ }^{1} \mathrm{H}$ NMR spectra of the homopolymer of TFONI and of copolymers exhibited the expected shifts at 6.0 (trans), 5.8 (cis), 5.1 (cis), 4.6 (trans) and 3.4 ppm.

\subsection{Synthesis and characterization of PU-POSS hybrid nanocomposites}

In this work, we have tried to incorporate both completely condensed POSS and incompletely condensed CyPOSS into the PU matrices. Hence, we have chosen the incompletely condensed CyPOSS molecule with a hydroxyl functional group to form urethane linkage with the isocyanate group. On the other hand, the completely condensed POSS-H molecule with hydride functional group, having an ability to react with the hydroxyl functional group of incompletely condensed CyPOSS molecule in the presence DBTDL catalyst (Schemes 3 and 4). The hybrid films synthesized were characterized using FTIR. FTIR technique was found to be quick and accurate method to determine the chemical 


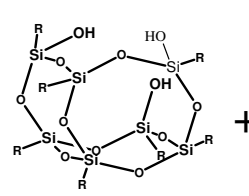

CyPOSS - OH

$$
90{ }^{0} \mathrm{C} \uparrow \mathrm{CH}_{3} \mathrm{CN} / \mathrm{H}_{2} \mathrm{O}
$$

$\mathrm{RSiCl}$

R: Cyclopentyl

TFONDI + POSS - ONDI

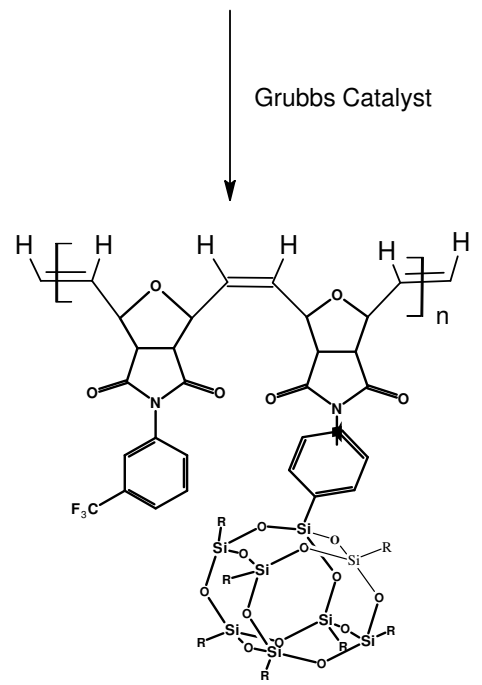

POSS - ONDI - TFONDI copolymers
$\mathrm{NEt}_{3}$

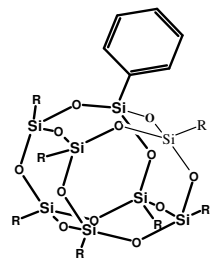

POSS - Ph

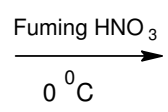

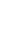

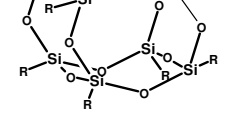

$\mathrm{POSS}-\mathrm{Ph}-\mathrm{NO}_{2}$<smiles>C=C1OC(=O)C2C3C=CC(C3)C12</smiles>
$90^{0} \mathrm{Cn} \downarrow \mathrm{CH}_{3} \mathrm{COOH}$ $\mathrm{CH}_{3} \mathrm{COONa} \quad\left(\mathrm{CH}_{3} \mathrm{CO}\right)_{2} \mathrm{O}$ $90^{0} \mathrm{C}$<smiles>O=C1C2C3CCC(O3)C2C(=O)N1c1cccc(C(F)(F)F)c1</smiles>

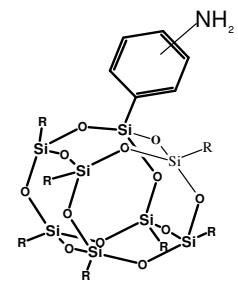
POSS - Ph - $\mathrm{NH}_{2}$

TFONDI

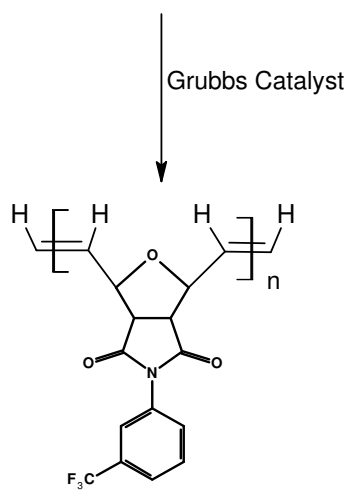

Homopolymer<smiles>C=C1OC(=O)C2C3C=CC(C3)C12</smiles>

$90^{\circ} \mathrm{C}$ $\mathrm{CH}_{3} \mathrm{COONa}$ $\left(\mathrm{CH}_{3} \mathrm{CO}\right)_{2} \mathrm{O}$

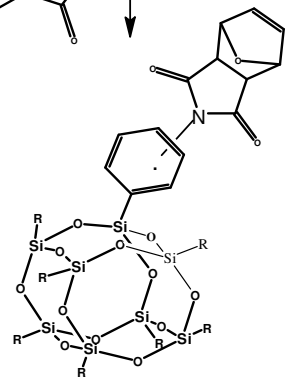

POSS - ONDI

Scheme 5. Synthesis of macromonomer, homopoly(TFONDI) and copolymers of POSSONDI and TFONDI 
structure of PU hybrids. The characteristic band near $2270 \mathrm{~cm}^{-1}$ represents the isocyanate group. This was completely disappeared in the IR spectrum of all the PU-POSS hybrid films, confirming that all the isocyanate molecules were completely reacted with the hydroxyl groups of CyPOSS and PDMS chain. On the other hand, the Si-H of POSS band near $2100 \mathrm{~cm}^{-}$ ${ }^{1}$ was also completely disappeared for all the PU-POSS films. We have anticipated that the $\mathrm{Si}-\mathrm{H}$ condensation reaction with $\mathrm{Si}-\mathrm{OH}$ in the presence of DBTDL catalyst may not proceed completely due to bulkiness of the POSS molecule. But in this case, surprisingly all the POSS was completely reacted and forming CyPOSS-POSS linkage and showing the complete distribution of POSS in the PU-POSS nanocomposites. The band near $1627 \mathrm{~cm}^{-1}$ shows the formation of $(\mathrm{C}=\mathrm{O})$ urethane linkage with $\mathrm{Si}-\mathrm{OH}$ group and $1590 \mathrm{~cm}^{-1}$ showing the formation of $(\mathrm{C}=\mathrm{O})$ urethane linkage by $\mathrm{CH}_{2}-\mathrm{OH}$. A very broad band near $3341 \mathrm{~cm}^{-1}$ corresponds to the hydrogen bonded N-H urethane linkage, which confirms the existence of hydrogen bond formation between the urethane linkages. PU-POSS hybrids show two bands at 1104 and $1013 \mathrm{~cm}-1$ corresponding to the Si-O-Si linkage of the POSS cubic structure and Si-O-Si linkage of the PDMS straight chain. The band at $1104 \mathrm{~cm}^{-1}$ (Si-O-Si cube) was observed in all the PU-POSS films suggesting that the POSS cube has remained intact during the nanocomposite formation.

\subsection{Thermogravimetric analysis of POSS-PDMS/PPG hybrid membranes \\ 3.5.1 Complete-POSS}

The thermal stability and degradation behaviour of PU-POSS hybrids were examined using TGA. The TGA was performed in the $\mathrm{N}_{2}$ atmosphere and the TGA values of PU-POSS hybrids were shown in Table 3. The POSS based hybrids show enhanced thermal properties like initial decomposition temperature (IDT) and the char yield values when compared with POSS free PU hybrids. The initial decomposition near $270^{\circ} \mathrm{C}$ is mainly attributed to the degradation of labile urethane group present in the hybrids. It was observed that the incorporation of increased wt \% of POSS molecules increases the IDT of the hybrids. The char yield values for the POSS incorporated hybrids show higher value $(20-30 \mathrm{wt} \%$ at $600^{\circ} \mathrm{C}$ ), indicating the rigid POSS cubes which remain stable even at higher temperatures. This indicates that the degradation of labile urethane group was controlled by the POSS rigid molecules. All the PPG soft segment based hybrids show decomposition pattern similar to the PDMS based hybrids. For all the hybrids, increase in the crosslinker (POSS) content increases the thermal properites of the hybrids. That means the IDT and char yield values increases with increase in the POSS content. This proves that POSS macromers improve the thermal properties of the hybrids to a greater extent. Zheng et al (2006) reported that the increase in POSS content does not alter the degradation pattern of the PU hybrids. But, the char yield values and $\mathrm{T}_{\max }$ varies with POSS content. The literature reported incorporation of POSS molecule enhances the thermal properties of the hybrids (Moreau et al, 2004). Based on the TGA results, it was possible to suggest that POSS nano cubes based hybrids possess enhanced thermal properties of hybrids.

\subsubsection{Incomplete-POSS}

The thermal stabilities of the PU-POSS hybrids were characterized with TGA under $\mathrm{N}_{2}$ atmosphere and the TGA data of PU-POSS hybrids were shown in Table 3. The initial decomposition for all the PU-POSS were similar and the initial decomposition (5 wt $\%)$ starts at $268^{\circ} \mathrm{C}$ for all the PU-POSS hybrids showing with excellent thermal stability. The decrease in 
the thermal properties was observed for PU-POSS hybrid films with increase in the addition of completely condensed POSS group. The CyPOSS substituted hybrid shows a very high thermal stability due to the presence of thermally stable cyclopentyl group in the vertices of CyPOSS group and likely the formation of more hydrogen bonding compared to methyl substitution in the POSS-H group. Incorporation of $2.5 \mathrm{Wt} \%$ of completely condensed POSS-H into the PU-POSS matrices show very high decrease in thermal properties of the PU-POSS-2 hybrid film. On further increase in the POSS-H incorporation, thermal properties slightly increased for the hybrids as observed in PU-POSS-3 and PU-POSS-4. But, the improved thermal properties of these hybrids were quite low compared to PU-POSS-1 hybrid film. The completely condensed POSS and incompletely condensed POSS incorporated PU-POSS hybrids (PU-POSS-2, PU-POSS-3 and PU-POSS-4) show two stage decomposition and the incompletely condensed POSS incorporated hybrid (PU-POSS-1) shows a single stage decomposition. These observations indicate that the completely condensed POSS molecule relatively affects the thermal properties of PU-POSS hybrids even at lower concentration. The final residue for PU-POSS-1 and PU-POSS-2 hybrids at $700^{\circ} \mathrm{C}$ remains the same, where as the residue increases in the case of PU-POSS-3 and PU-POSS-4 hybrids with increase in the concentration of completely condensed POSS. This clearly shows that the POSS-H aggregates remain unaltered even at $700^{\circ} \mathrm{C}$ but the contribution of completely condensed POSS-H for the polymer matrices as a whole towards thermal properties appears to be very less. From these observations, it was concluded that the nature of the POSS group, reactive functional group in the POSS molecule and the rigid bulky group on the vertices of the POSS were the three main factors which significantly alter the thermal properties of the hybrids.

\subsubsection{Copolymers of POSS-ONDI and TFONDI}

The decomposition temperature and the char yield values of the polymers were listed in Table 2. It was observed that the incorporation of POSS (e.g., copolymers of POSS-ONDI) decreased the thermal stability of the polymers, whereas TFONDI homopolymer showed very high thermal stability. The addition of POSS decreased the thermal stability of POSSONDI copolymers due to the disruption of close packing of the polymer units by the bulky POSS groups and leads to an increase in the free volume between the polymer chains. The overall observation suggests that the POSS molecule affects the thermal properties of polymers of $\mathrm{N}$-(POSS)-7-oxanorbornene-5,6- dicarboximide nanocomposites even at low concentrations.

\subsection{Differential scanning calorimetric analysis.}

The DSC values of POSS incorporated hybrid membranes were shown in Table 3 . The POSS/PPG incorporated hybrids show two distinct glass transition temperatures (Tg's). The lower Tg values around -48 to $-40^{\circ} \mathrm{C}$ was attributed to the PPG soft segment and the $\mathrm{Tg}$ around $179-185^{\circ} \mathrm{C}$ was due to the PU hard segment (Reddy et al 2009). The Tg values of POSS incorporated hybrids were given in Table 3 . The Tgs corresponding to the hard segment increases drastically with increase in the POSS incorporated hybrid membranes. This indicates that the POSS rigid cube restricts the free rotation of the macromolecular chains to a greater extent.

The nanocomposite membranes showed an enhanced $\mathrm{Tg}$, with increase in the POSS content. The Tgs at 197,191 , and $220^{\circ} \mathrm{C}$ were observed for 5,15 , and $25 \mathrm{wt} \%$ of POSS incorporated membranes, respectively. The increase in Tg for POSS incorporated membranes was due to 


\begin{tabular}{lcccc}
\hline SAMPLE & $\mathrm{T}_{5}\left({ }^{\circ} \mathrm{C}\right)$ & $\mathrm{T}_{50}\left({ }^{\circ} \mathrm{C}\right)$ & $\begin{array}{c}\text { Char yield at } \\
600{ }^{\circ} \mathrm{C}(\%)\end{array}$ & $\mathrm{Tg}_{(\mathrm{Hs})}\left({ }^{\circ} \mathrm{C}\right)$ \\
\hline PU-POSS-1 & 268 & 465 & 10 & 195 \\
PU-POSS-2 & 268 & 413 & 8 & 197 \\
PU-POSS-3 & 269 & 404 & 15 & 191 \\
PU-POSS-4 & 270 & 388 & 10 & 220 \\
POSS-PDMS-5 & 225 & 380 & 22 & 179 \\
POSS-PDMS-15 & 250 & 382 & 25 & 185 \\
POSS-PDMS-25 & 260 & 390 & 28 & 189 \\
POSS-PPG-5 & 270 & 380 & 17 & 180 \\
POSS-PPG-15 & 273 & 365 & 20 & 183 \\
POSS-PPG-25 & 275 & 385 & 26 & 185 \\
\hline
\end{tabular}

Table 3. TGA and DSC Values for PU-POSS, POSS-PDMS and POSS-PPG based PU hybrid nanocomposites

the nano-reinforcement of POSS molecule in the polymer matrices, which restricts the motions of polymer chains (Madhavan and Reddy, 2009). Tgs at 197, 191, and $220^{\circ} \mathrm{C}$ were observed for PU-POSS-2, PU-POSS-3 and PU-POSS-4 nanocomposite membranes, respectively.

The glass transition temperature of the POSS-ONDI nanocomposites was significantly enhanced by the incorporation of $25-w t \%$ of POSS units. This may be due to the restricted motion of the polymer chains caused by the even distribution of bulky POSS units at the segmental level and increased rotational barrier of the polymers at low POSS concentration. But, the Tg values were lowered when the loading of POSS units increased to 50 or $75-w t \%$. This effect could be possibly explained by the fact that the bulky POSS creates more chain spacing resulting in the increase in free volume with larger fraction of low molecular weight component giving raise to the decrease in the $\mathrm{Tg}$ values.

\subsection{Dynamic mechanical analysis}

\subsubsection{Complete-POSS}

The storage modulus values (E') of PU hybrids were shown in Table 4. It was observed that $\mathrm{E}^{\prime}$ was increased by incorporating a small amount of POSS into the hybrid. E' values for all the POSS hybrids were higher than those of linear PDMS chain incorporated hybrids. The E' values at $30^{\circ} \mathrm{C}$ were found to be 9.1, 14.6, 18.2, 29.2, 32.1 and 35.0 for POSS-PDMS-5, POSSPDMS-15, POSS-PDMS-25, POSS-PPG-5, POSS-PPG-15 and POSS-PDMS-25 respectively. The increasing \% of POSS incorporated hybrids show three fold greater than that of the free POSS content hybrids. This implies that the incorporation of the POSS nanoparticles play an important role in the viscoelastic behaviour of the synthesized hybrids. The hybrids show a very long range of rubber plateau region since all the hybrids contains almost $90 \%$ of both the PPG and PDMS soft segments. The enormous increase in the storage modulus of the nanohybrids even at low concentration of $15 \mathrm{wt} \%$ of POSS (POSS-PDMS-15) incorporation confirms that the contribution of POSS cage structure towards the increase in viscoelastic properties of the nanohybrids. The Tg values significantly increased with the increase in the incorporation of the POSS content as explained in the DSC analysis. The Tg values obtained through DSC measurements were found to be in good agreement with the Tg values 
obtained from the DMA measurements. For the POSS incorporated PU hybrids, the tan $\delta$ values were found to be very high and the peaks were broadened, when compared to the PDMS incorporated PU hybrids. The high $\delta$ peaks show even distribution of POSS molecules in the PU network structure.

\begin{tabular}{lcccc} 
Sample & $\begin{array}{c}\text { Storage } \\
\text { Modulus (E') } \\
\text { at 30॰C }\end{array}$ & $\begin{array}{c}\text { Tg (PDMS soft } \\
\text { segment) }\end{array}$ & $\begin{array}{c}\text { Tg (PPG soft } \\
\text { segment) }\end{array}$ & $\begin{array}{c}\text { Tg } \\
\text { (HS) }\end{array}$ \\
\hline POSS-PDMS-5 & 9.1 & -112 & - & 162 \\
\hline POSS-PDMS-15 & 14.6 & -104 & - & 164 \\
\hline POSS-PDMS-25 & 18.2 & -101 & - & 169 \\
\hline POSS-PPG-5 & 29.2 & -105 & -33 & 168 \\
\hline POSS-PPG-15 & 32.1 & -107 & -29 & 170 \\
\hline POSS-PPG-25 & 35.0 & -108 & -23 & 175 \\
\hline
\end{tabular}

Table 4. DMA results of POSS-PDMS and POSS-PPG based PU hybrid nanocomposites

\subsubsection{Incomplete-POSS}

The bending storage modulus ( $\left.E^{\prime}\right)$ versus temperature curves at $0.1 \mathrm{~Hz}$ for PU-POSS hybrids were shown in Figure 8. The decrease in $\mathrm{E}^{\prime}$ with increase in the concentration of completely condensed silsesquioxane was observed. E' value of PU-POSS-1 was higher than that of the mixed CyPOSS and POSS hybrid films such as PU-POSS-2, PU-POSS-3, and PU-POSS-4. This is due to the CyPOSS-urethane interaction with polymer matrix and the formation of hydrogen bonding in the case of PU-POSS-1. The decrease in the storage modulus of PUPOSS-2, PU-POSS-3 and PU-POSS-4 perhaps attributed to the formation of hydrophobic

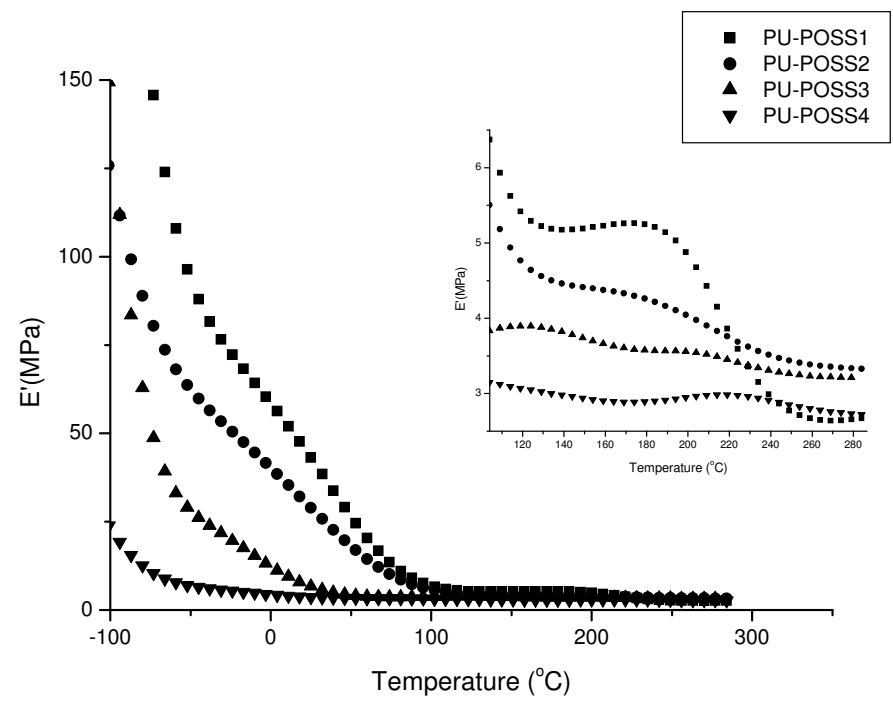

Fig. 8. The storage modulus (E') Versus Temperature curves of PU-POSS hybrid nanocomposites 
CyPOSS-POSS aggregates in the matrices. This in turn reduces the interchain interactions and interrupts the PU hydrogen bonding formation. All these factors suggest that the contribution of POSS cage structure alone may not be enough to improve the mechanical properties. However, the cage interaction with the polymer matrix and their functional groups were all highly dependent on each other.

\subsection{Atomic Force Microscopy (AFM)}

Surface morphology of PU-POSS nanocomposite membranes was examined by AFM. The images of PU-POSS-2 and PU-POSS-4 were shown in Figures 9 and 10. It was observed clearly that the spherical domains correspond to POSS clusters which spread over the surface of the membranes. This may be most likely due to the incompatible nature of POSS molecule with polymer matrices and confirms that even the crosslinking of POSS with polymer matrices through functional group will not restrict the formation of aggregation of a POSS nanoparticle (Madhavan and Reddy, 2009). In the case of nanocomposite

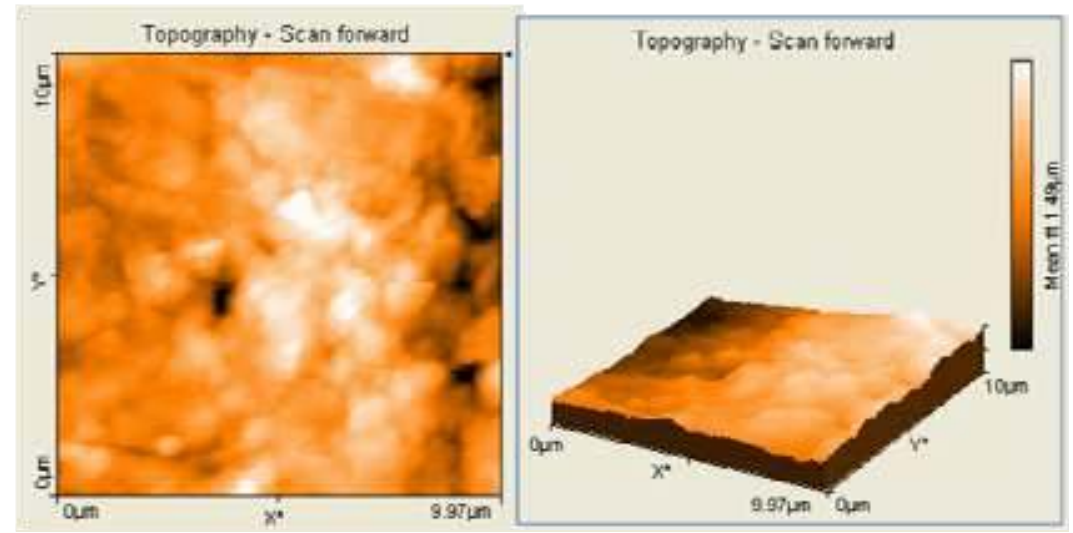

Fig. 9. AFM images of PU-POSS-1
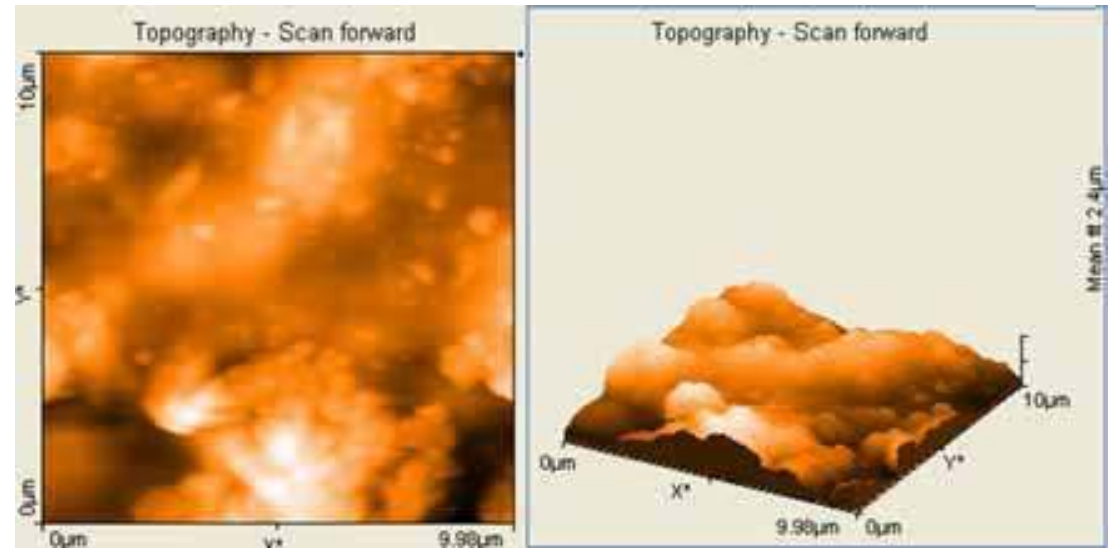

Fig. 10. AFM images of PU-POSS-2 
membranes with POSS nanoparticles show more granular type POSS aggregates with rough membrane surface area indicating that the surface morphology of membranes was highly affected by the addition of POSS molecule to PU-POSS membranes. The AFM image reveals a highly heterogeneous morphology reflecting the less dispersive nature of POSS molecules with PDMS-PU hybrids.

The AFM image of TFONDI was slightly different from the POSS incorporated nanocomposites, showing a smooth surface having microphase separated morphology. It was observed that a uniform distribution of spherical POSS aggregates dispersed in the nanocomposites. In the case of our systems, the aggregation of POSS might be created by self-assembling of POSS.

\subsection{Transmission Electron Microscopy (TEM)}

TEM imaging analysis of the polymers (Fig.11) provide further information about the POSS dispersion in the polymer matrix. No particles could be observed for the transparent TFONDI. However, transmission electron microscopy of POSS25-ONDI revealed nano-sized POSS clusters with varying sizes ranging from $50 \mathrm{~nm}$ examined in various areas of the film surface. TEM imaging POSS domains were darker than the polymer matrix because of their higher mass contrast in comparison with polynorborene-imide chains. This observation also showed that the discreetly sized POSS cage aggregates were well dispersed within the bulk polymer (Zeng and Zheng, 2007).
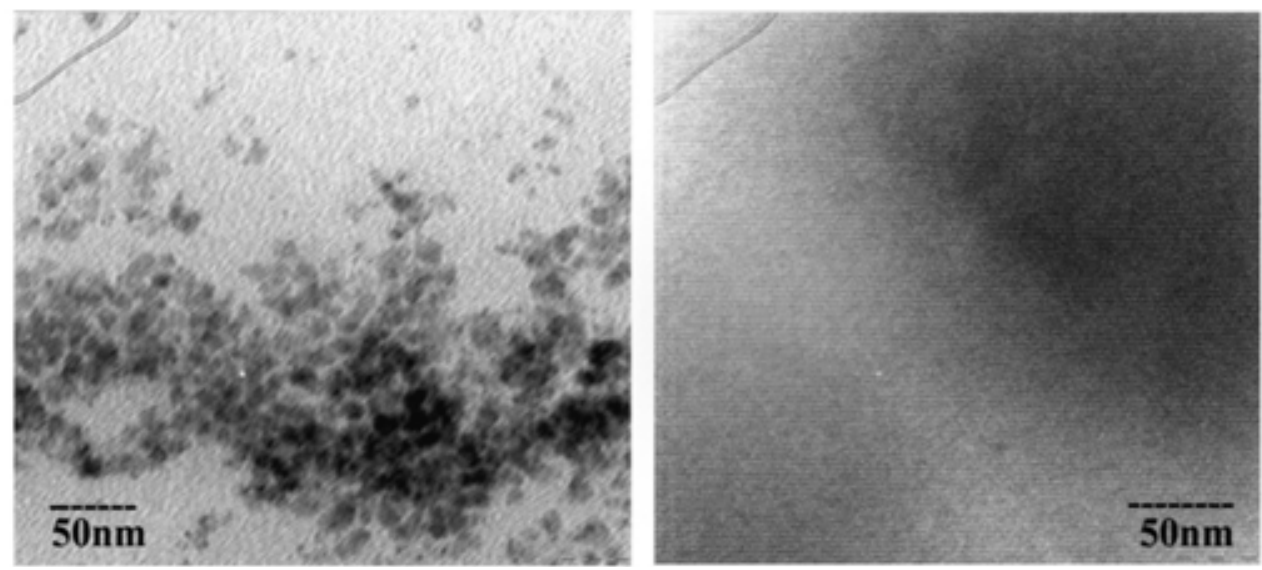

Fig. 11. TEM images of homopolymer of TFONDI (right) and copolymer of POSS25-ONDI (left).

\subsection{Scanning Electron Microscopy (SEM) analysis}

Figure 12 display SEM images of the bulk morphology of PU-POSS-1, PU-POSS-2, PUPOSS-3 and PU-POSS-4 hybrid films. All the PU-POSS films show a microphase separation of urethane hard segments and a micro/nano level spheroidical aggregation of POSS rich domains. Similar observations were reported (Zhang et al, 2006) about the aggregation of POSS from nano- to micro- level, and the hydrogen bonding increases the compatibility in the phenolic reisn-POSS hybrid nanocomposites. It can be clearly seen in the SEM images that the POSS aggregates in to POSS rich spheroidical domains in the PU-POSS hybrid films. But the type of aggregation of POSS groups and the phase separation in the all films were 


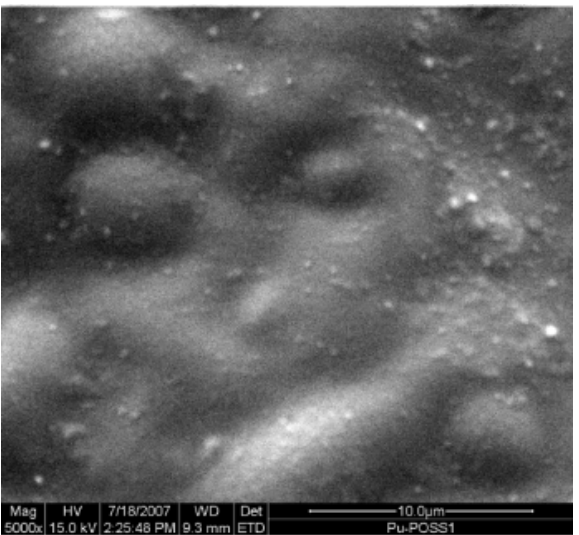

PU-POSS-1

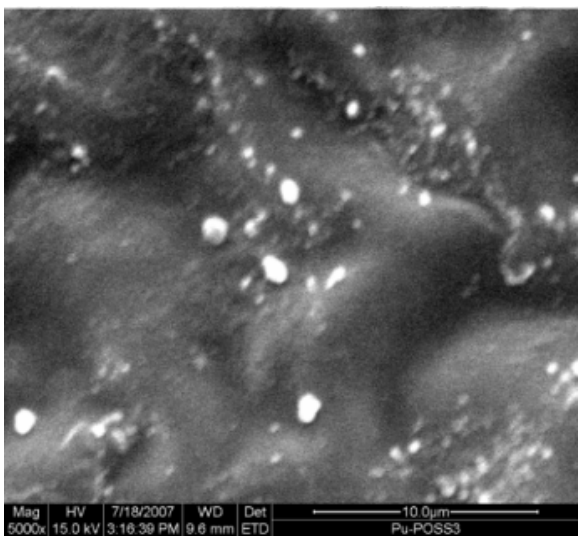

PU-POSS-3

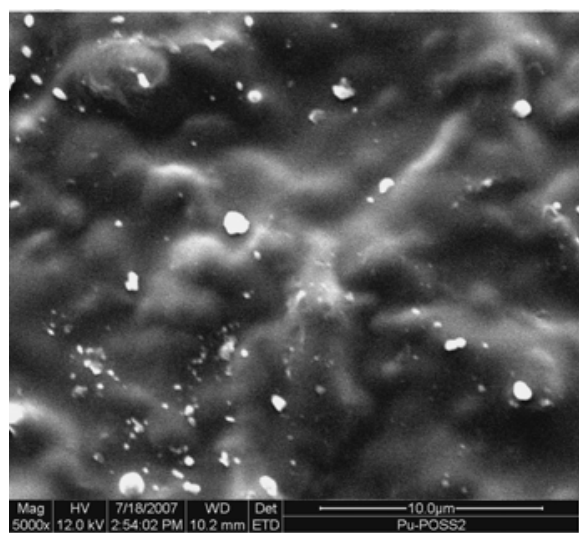

PU-POSS-2

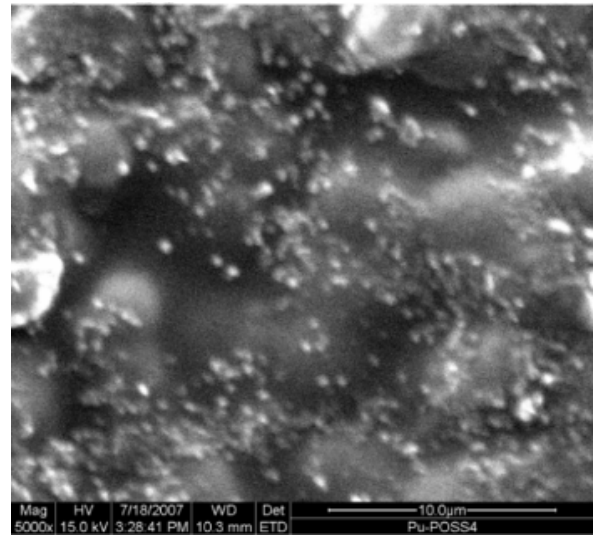

PU-POSS-4

Fig. 12. SEM images of PU-POSS nanocomposites

found to be different. There was an excellent dispersion of CyPOSS-urethane aggregates in the PU-POSS-1 film. The aggregations were not homogeneous in the case of PU-POSS-2, PUPOSS-3 and PU-POSS-4 films and were highly phase separated from the polymer matrix. The excellent dispersion of CyPOSS-urethane aggregates in the PU-POSS-1 was explained by the combination of three factors. i) The reactivity of trisilanol group with isocyanate so that it can incorporate CyPOSS evenly in the network during the early stages of the polymerization. ii) The high compatibility of CyPOSS in the PU matrices rather than completely condensed POSS-H, where the CyPOSS interacts highly with the polymer matrices. iii) The possibility of favourable CyPOSS- CyPOSS organisation in the PU matrices. The combination of these three factors create a homogeneous aggregation of CyPOSS-urethane and even distribution of aggregates in the polymer matrices (Madhavan et al, 2009). The PU-POSS-2, PU-POSS-3 and PU-POSS-4 hybrids show a large fraction of POSS aggregation and inhomogeneous aggregations. This may be due to the formation of hydrophobic CyPOSS-POSS aggregates, which seems to be having less interaction with polymer matrices. The fraction of POSS aggregation increases with increasing in the addition of completely condensed POSS-H cage structure. 


\subsection{Wide-Angle X-ray Diffraction (WAXD)}

1) The microstructure of PU-POSS hybrids was of further interest to us and studied using the WAXD measurements. Fig. 13. displays XRD patterns of PU-POSS hybrids. For comparison, the diffraction patterns of pure CyPOSS and POSS-H were also shown. The pure Cy-POSS and POSS-H molecules show crystalline peaks at $2 \theta=7.0^{\circ}, 10.2^{\circ}, 11.5^{\circ}$, and $18.3^{\circ}$. All the crystalline peaks of Cy-POSS and POSS-H peaks were absent in the PU-POSS hybrid films. This implies that the crystallinity of POSS molecules were collapsed by the polymer matrices in the PU-POSS hybrids. A broad peak at $2 \theta=11.3^{\circ}$ in all the hybrids was observed, which may be due to the amorphous nature of the PDMS matrices. These observations could reflect that the absence of crystalline microdomains in the POSS rich phase and also confirms the absence of macrolevel POSS aggregation in the PU-POSS hybrids.

2) The WAXD pattern of POSS-PDMS-25 and POSS-PPG-25 hybrid membranes were measured and the results were shown in Fig. 14. A broad diffraction intensity was observed around $2 \theta=11.0-13.5^{\circ}$ which may be due to amorphous PDMS soft segment present in the matrices. It could be seen that a very weak peak $c a$ at $2 \theta=18.3-21.0^{\circ}$ in the hybrids reflect the amorphous PU groups present in the membrane matrix. After hybridization, the crystalline peaks of bulky POSS groups were absent in the membrane matrices showing that the membranes were found to be highly amorphous in nature. Similar observations were reported by Chang et al, 2004 .

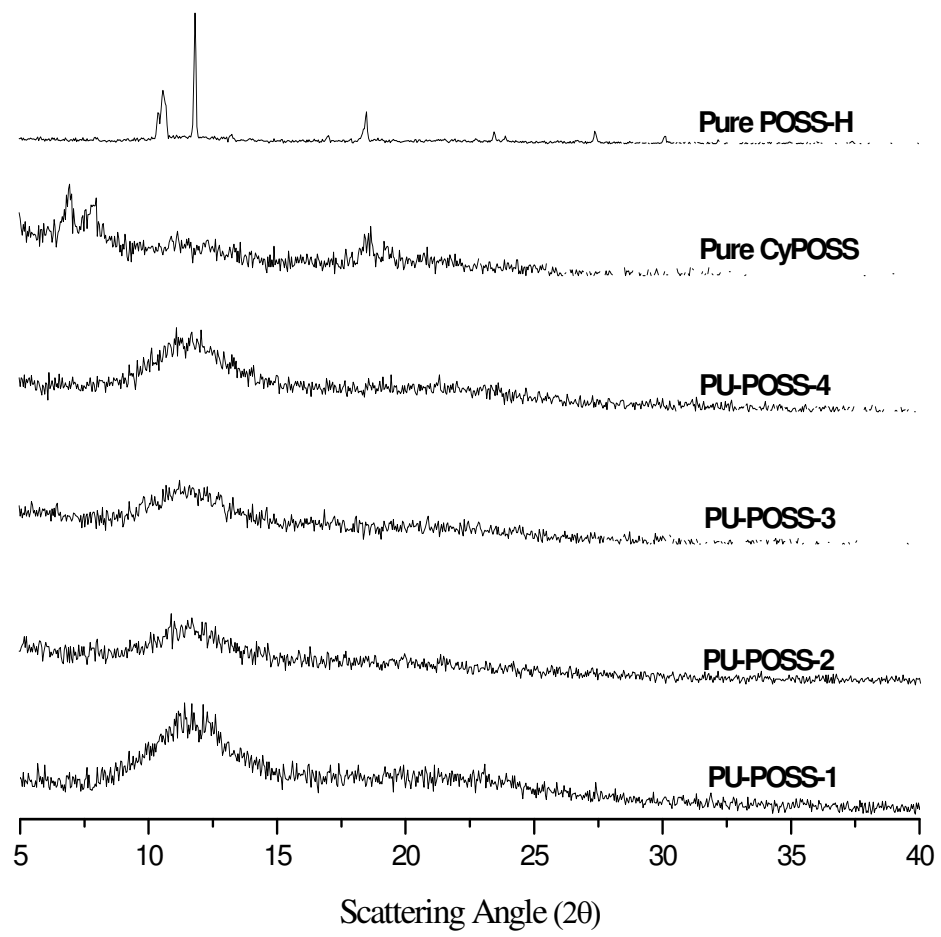

Fig. 13. WAXD curves of Pure-POSS-H, Pure-CyPOSS and PU-POSS hybrid nanocomposites 

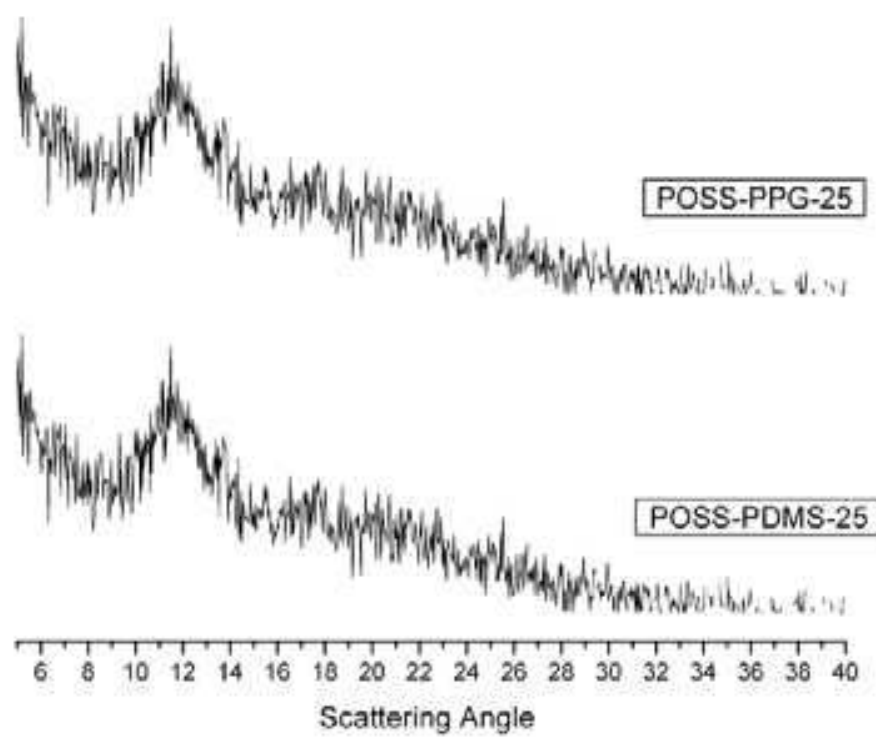

Fig. 14. WAXD curves of POSS-PPG-25 and POSS-PDMS-25 hybrid nanocomposites

\subsection{Pressure dependency of permeability of membranes}

Solution-diffusion transport model was applied for gas transport process through dense polymer film. The permeability coefficient $\left(P_{\mathrm{A}}\right)$ of a penetrant through a membrane was measured as a steady state flux $\left(N_{\mathrm{A}}\right)$, normalized by partial pressure difference $\left(\Delta P_{\mathrm{A}}\right)$ and membrane thickness $(d)$.

$$
P_{A}=N_{A} \frac{d}{\Delta P_{A}}
$$

Permeability is frequently expressed in Barrers, where 1 Barrer $=10^{-10} \mathrm{~cm}^{3}(\mathrm{STP}) \mathrm{cm} / \mathrm{cm}^{2} \mathrm{~s}$ $\mathrm{cmHg}$. Permeability coefficient of a particular penetrant can also be expressed as the product of a kinetic factor, the diffusion coefficient $\left(D_{\mathrm{A}}\right)$, and a thermodynamic factor, the sorption or solubility coefficient $\left(S_{\mathrm{A}}\right)$.

$$
\mathrm{P}_{\mathrm{A}}=\mathrm{D}_{\mathrm{A}} \mathrm{S}_{\mathrm{A}}
$$

Membrane separation performance is characterized by ideal selectivity of a membrane, $\propto_{\mathrm{A} / \mathrm{B}}$ when the downstream pressure is negligible. This ideal selectivity is defined as the ratio of permeabilities of two gases and is the product of diffusivity selectivity $D_{\mathrm{A}} / D_{\mathrm{B}}$ and solubility selectivity $S_{\mathrm{A}} / S_{\mathrm{B}}$, of two gases in the membranes.

$$
\propto_{A / B}=\frac{P_{A}}{P_{B}}=\left(\frac{D_{A}}{D_{B}}\right)\left(\frac{S_{A}}{S_{B}}\right)
$$

Permeability of $\mathrm{N}_{2}$ and $\mathrm{O}_{2}$ gases drastically decreases with the increase in penetrant pressure for all the POSS incorporated membranes. This may be due to two factors. (i) When 
the penetrant pressure increases, there must be a compression of polymer matrix which leads to reduction in the free volume for penetrant transport. This in turn reduce penetrant gas diffusion coefficient. (ii) The other factor may be due to the dispersion of POSS aggregates on the surface of membranes, which restricts the interaction of penetrant with the surface of the membrane matrices. If the penetrant's pressure increases, adsorption of lighter gases on the surface of membrane may likely decreases due to the POSS aggregates. This leads to a decrease in permeability of gases. In the case of $\mathrm{CO}_{2}$, the permeability was found to be quite different and increases with the increase in pressure. This perhaps may be due to more condensable nature of $\mathrm{CO}_{2}$ gas. Also, by increase in pressure, the adsorption of $\mathrm{CO}_{2}$ gas on the surface of membranes seems to be high and the diffusion of $\mathrm{CO}_{2}$ gas was more when compared to that of $\mathrm{N}_{2}$ andO $\mathrm{O}_{2}$ gases. But, it was observed that at higher POSS content the increasing order of $\mathrm{CO}_{2}$ permeability was slightly reduced with pressure, due to the restriction of interaction of $\mathrm{CO}_{2}$ with membrane matrix by the presence of POSS aggregates. Incorporation of nonporous (impermeable) nanoparticles to polymer membranes unfortunately tends to reduce penetrant's permeability. This effect can be accurately modelled by Maxwell's relationship (Maxwell 1873) originally derived to describe the dielectric properties of suspension of spheres and this can also be used to model permeability of membranes filled with spherical impermeable particles. In this work, we have observed that the CyPOSS content in all the compositions decreases permeability drastically in $\mathrm{N}_{2}, \mathrm{O}_{2}$, and $\mathrm{O}_{2}$ gases (Maxwell relationship). This indicates that increase in the CyPOSS nanoparticle volume fraction tends to reduce the permeability. But, many researchers reported that the incorporation of inorganic nanoparticles like fumed silica in polymeric membrane leads to increase in permeability of gases, showing non-Maxwellian's effect (Moaddeb and Koros, 1997; Patel, 2003). Cong et al, 2007 explained the nonMaxwellian's effect of nanocomposite membranes was due to poor compatibility between silica surface and the polymer chains. This could not organise the nanoparticles to have tight packing, whereby forming a narrow gap surrounding the nanoparticles. The gas diffusion path was shortened and thus apparent gas diffusivity and permeability were increased. On the other hand, non-Maxwellian's effect was described using a slightly different phenomenon where silica nanoparticles were small enough to disrupt polymer chain packing in the polymers. This resulted in an increase in polymer fractional free volume which increases the permeability of the membranes. Similar observations were made by Gonzalez et al, (2006) who reported an increase in POSS concentration increases the permeability of all gases due to nanocracks or nanogap formation in the membranes. But, modified silica nanoparticle (Cong et al, 2007) incorporated membranes show decrease in permeability of gases. Similar decrease in the permeability with increase in POSS concentration was observed in the case of CyPOSS incorporated nanocomposite membranes. Lin and Freeman reported a drastic decrease in permeability in the case of poly(trimethylsilylpropyne) membrane containing POSS nanoparticles. The CyPOSS nanoparticle incorporated PDMS-PU membranes show decrease in permeation with increase in POSS concentration for all gases (Maxwell's effect). But, surprisingly there was slight increase in the permeability when the POSS-H content was added to CyPOSS incorporated membranes (non-Maxwell's effect). This may be due to the poor compatibility of POSS-H aggregates forming heterogeneous dispersion over the membranes. This causes the disruption of polymer chain packing and resulted an increase in the free volume. The 
increase in free volume was well corroborated with the decrease in the measurement of density of the membranes. Based on the above observations, it was predicted that the compatibility of POSS nanoparticles alter the permeation of diffusing molecules. POSS molecule either aids the formation of more free volume or provides torturous route for penetrant diffusion depending upon the compatibility. In the case of CyPOSS incorporated nanocomposite membranes, the dispersed POSS phases act as a blocking agent and produce higher resistance route for diffusing molecules.

\subsection{Selectivity of the membranes}

Selectivity of $\mathrm{O}_{2} / \mathrm{N}_{2}$ gas pair was in the range of 1.9-2.4 and for $\mathrm{CO}_{2} / \mathrm{N}_{2}$ was 7.4-14.9. Figs. 15 and 16 represent $\mathrm{O}_{2} / \mathrm{N}_{2}$ and $\mathrm{CO}_{2} / \mathrm{N}_{2}$ gas pair selectivities of membranes as a function of pressure. The $\mathrm{O}_{2} / \mathrm{N}_{2}$ gas pair selectivities increased slightly with the increase in POSS content as well as with pressure. This seems to be mainly due to high interactions between $\mathrm{O}_{2}$ gas and high concentration of silicon and oxygen atoms that constitute POSS cage. It is reported that $\mathrm{O}_{2}$ gas has more interaction with the polar groups and silicon atoms of polymers that lead to higher solubility of oxygen gas in the membranes (Khotimskii et al, 2000). In the case of CyPOSS incorporated membranes, an increase in the POSS content leads to the presence of either more urethane linkages or unreacted triol functional groups of POSS and Si atoms of POSS molecules in the membranes. But, the addition of POSS-H to

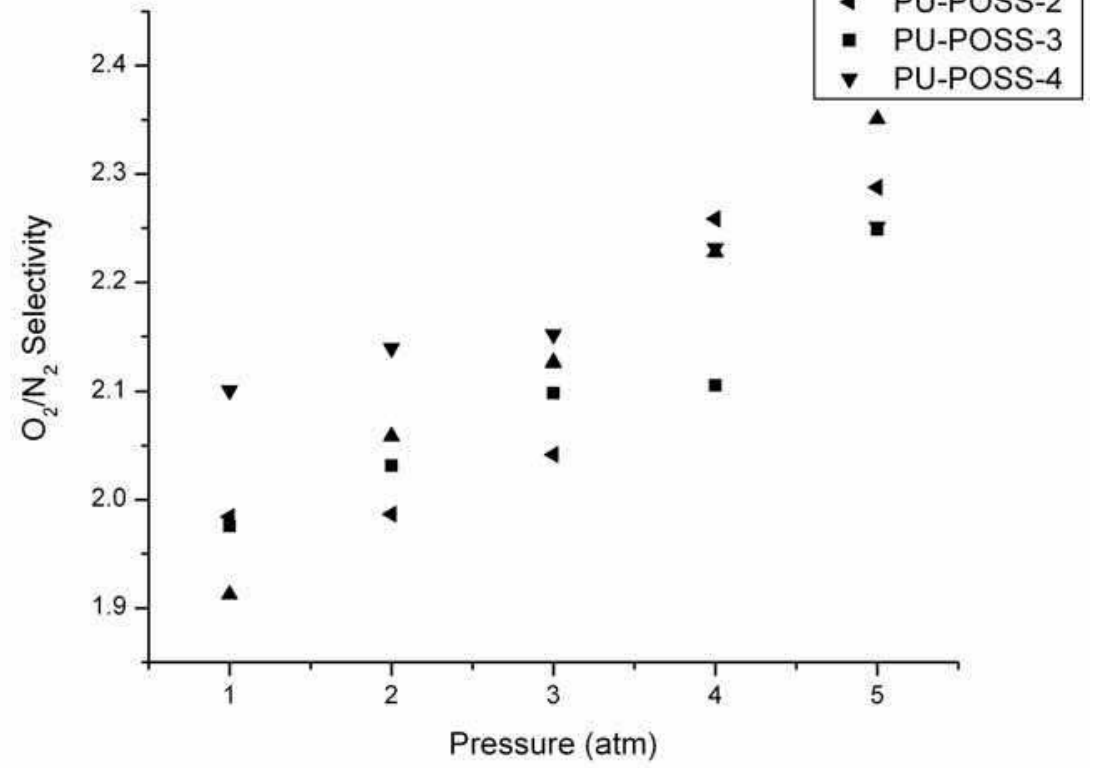

Fig. 15. O2/N2 gas pair selectivity as a function of pressure. 


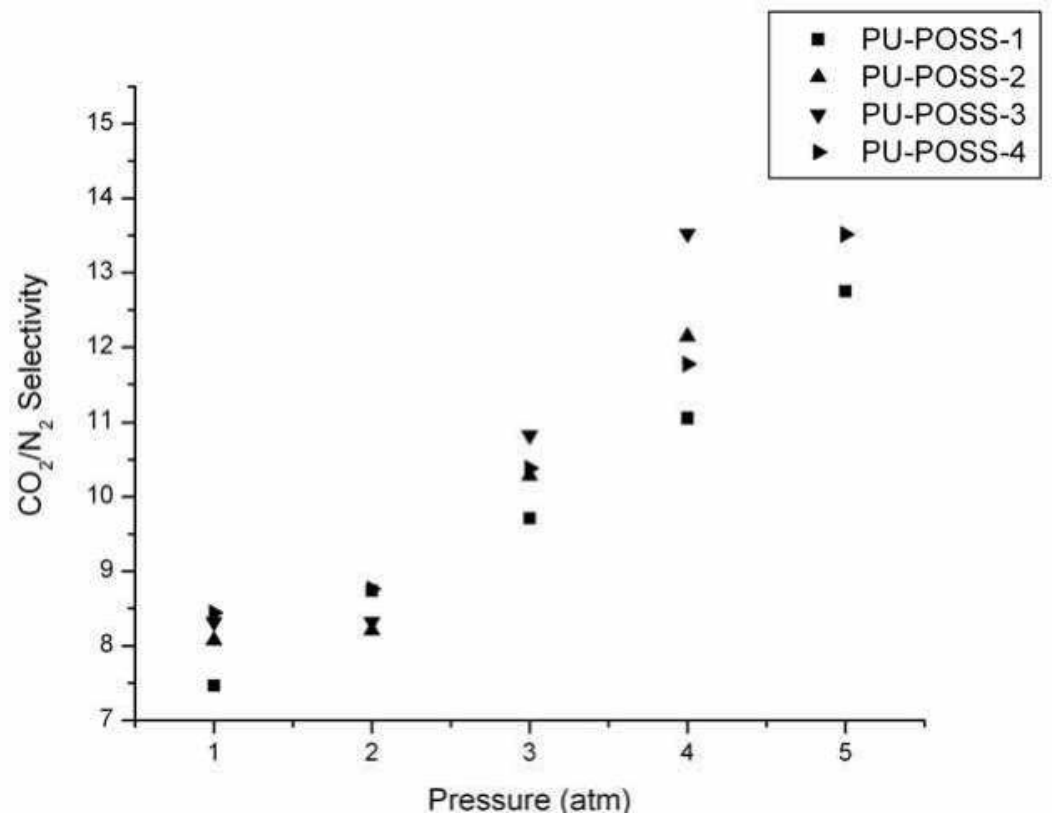

Fig. 16. $\mathrm{CO}_{2} / \mathrm{N}_{2}$ gas pair selectivity as a function of pressure.

nanocomposite membranes does not increase the $\mathrm{O}_{2} / \mathrm{N}_{2}$ selectivity. This might be due to the restriction in the formation of urethane linkages by the POSS-H molecule as we have reported earlier (Madhavan et al 2009). Likewise, the selectivities of $\mathrm{CO}_{2} / \mathrm{N}_{2}$ gas pair increases from 7.4 to 14.9 with an increase in POSS content and pressure, whereas $\mathrm{CO}_{2} / \mathrm{N}_{2}$ selectivity was slightly decreased by the addition of POSS-H nanoparticles. This shows that selectivity parameter was controlled by the diffusion of gas molecule through the urethane polar groups rather than the POSS aggregates in the membrane.

\section{Conclusions}

A new class of ester, aliphatic, aromatic-amine functionalised silsesquioxane macromers, completely condensed and incompletely condensed POSS were synthesised and these macromers were used to synthesize poly(ester-urethane), polyimide and polyurethanePOSS nanocomposites. Linear poly(dimethylsiloxane) was also synthesized to study the influence of different $\mathrm{wt} \%$ of silsesquioxane macromer, PDMS macromer and a series of PUPOSS hybrids consisting of various compositions of completely condensed and incompletely condensed POSS hybrids were synthesized. Thermal, mechanical, morphological and surface properties of POSS based hybrids were studied using TGA, DSC, SEM, TEM and 
AFM. Based on the char yield values of the hybrids, it was observed that a slight increase in the thermal properties of the silsesquioxane incorporated PU networks than that of the linear PDMS macromer incorporated hybrids. The TGA thermograms of the macromers reveal that the thermal stability depends on both the functional group substituted and the structure on the siloxane compound. The DSC values of macromers show that the thermal transitions were mainly dependent on the functional group substituted in the inorganic core. The glass transition temperatures of the POSS incorporated PU networks increases with increase in the $w \mathrm{t} \%$ of POSS. This may be due to the increasing number of bulky POSS which makes the membrane to vibrate the polymer chain giving rise to higher Tgs. The surface morphology was highly affected by the POSS molecule and this may be due to formation of nano/micro level spheroidical aggregations. The mechanical and thermal properties were enhanced by the formation of these aggregates since these aggregates act like spacers between the polymer chains due to its incompatible nature with the PU-POSS matrices. TEM and AFM micrographs of nanocomposites were consistent with a selfassembled spherical aggregation of POSS dispersed in POSS based nanocomposites. The absence of crystalline domains due to POSS molecule in the membranes were found to be highly suitable for gas separation process since the crystalline domains in the membrane affect the permeability of gases. Permeability measurement reveals that the permeability of $\mathrm{N}_{2}$ and $\mathrm{O}_{2}$ gases decreases with the increase in pressure. The permeability of all the gases decreases with the increase in the incomplete condenced-POSS nanoparticle concentration. But, addition of a small concentration of complete condenced-POSS nanoparticles to incomplete condenced-POSS based membrane increases permeability while selectivity of $\mathrm{O}_{2} / \mathrm{N}_{2}$ gas pair decreases. This reveals that the nature and compatible of POSS groups alter the permeability of gases and the polar urethane linkages play a vital role in the gas pair selectivities of nanocomposite membranes. The selectivity of $\mathrm{O}_{2} / \mathrm{N}_{2}$ gas pair was in the range of 1.9-2.4 and for $\mathrm{CO}_{2} / \mathrm{N}_{2}$ pair from 7.4 to 14.9. The overall conclusion drawn from all the observations was that the rigid POSS cubic cage structure alone was not imparting the properties to the bulk polymer, but the functional group, compatibility of the POSS molecule with the polymer matrices and bulky substituents in the vertices of the POSS molecules alters the bulk properties of the polymers.

\section{Acknowledgements}

One of us D.G thanks the Department of Science and Technology, New Delhi (No. SR/S1/PC-33/2006) for the Junior Research Fellowship.

\section{References}

Achalpurkar, M.P.; Kharul, U.K.; Lohokare, H.R. \& Karadkar, P.B. (2007). Gas permeation in amine functionalized silicon rubber membranes, Separation and Purification Technology. 57 304-313.

Brick, C. M.; Ouchi, Y.; Chujo, Y. \& Laine, R. M. (2005). Robust Polyaromatic octasilsesquioxanes from polybromophenylsilsesquioxanes, $\mathrm{Br}_{x} \mathrm{OPS}$, via Suzuki Coupling, Macromolecules, 38 4661-4665. 
Chang, Y. T.; Shu C. F.; Leu, C. M. \& Wei, K. H. (2003). Synthesis and characterization of hyperbranched aromatic poly(ether imide)s with terminal amino groups, Journal Polymer Science: Part A: Polymer Chemistry, 41 3726-3735.

Cong, H.; Hu, X.; Radosz, M. \& Shen, Y. (2007). Brominated poly(2,6-diphenyl-1,4phenylene oxide) and its $\mathrm{SiO} 2$ nanocomposite membranes for gas separation, Industrial Engineering Chemistry Reseasch. 46 2567-2575.

Cong, H.; Radosz, M.; Towler, B.F. \& Shen, Y. (2007). Polymer-inorganic nanocomposite membranes for gas separation, Separation and Purification Technology. 55 281-291.

Electric generation using natural gas, website for organization of natural gas, 2009. http://www.naturalgas.org/overview/uses eletrical.asp.

Fu, B. X.; Hsiao, B. S.; Pagola, S.; Stephens, P.; White, H.; Rafailovich, M.; Sokolov, J.; Mather, P. T.; Jeon, H. G.; Phillips,

S.; Lichtenhan, J. \& Schwab, J. (2001), Structural development during deformation of polyurethane containing polyhedral oligomeric silsesquioxanes (POSS) molecules, Polymer 42 599-611.

Gnanasekaran, D.; Madhavan, K. \& Reddy, B.S.R. (2009). Developments of polyhedral oligomeric silsesquioxanes (POSS), POSS nanocomposites and their applications: A review Journal of Scientific Industrial Research, 68 437-464

Gnanasekaran, D. \& Reddy, B.S.R. (2010). Synthesis and Characterization of nanocomposites based on copolymers of POSS-ONDI macromonomer and TFONDI: Effect of POSS on thermal, microstructure and morphological properties. Advanced Materials Research. 123-125 775-778.

Genne, I.; Kuypers, S. \& Leysen, R. (1996). Effect of the addition of $\mathrm{ZrO} 2$ to polysulfone based UF membranes, Journal of Membrane Science, 113 343-350.

Gomes, D.; Nunes, S.P. \& Peinemann, K.V. (2005). Membranes for gas separation based on poly(1-trimetylsilyl-1-Propyne)-silica nanocomposites, Journal of Membrane Science, 246 13-25.

Haddad, T.S. \& Lichtenhan, J.D. (1996). Hybrid Organic-Inorganic Thermoplastics: StyrylBased Polyhedral Oligomeric Silsesquioxane Polymers, Macromolecules, 29 73027304 .

Hong, B.; Thoms, T. P. S.; Murfee, H. J. \& Lebrun, M. J. (1997). Highly branched dendritic macromolecules with core polyhedral silsesquioxane functionalities, Inorganic Chemistry, 36 6146-6147.

Huang, S.L. \& Lai, J.Y. (1995). On the gas permeability of hydroxyl terminated polybutadiene based polyurethane Membranes, Journal of Membrane Science, 105 137-145.

Ikeda, M. \& Saito, H. (2007). Improvement of polymer performance by cubicoligosilsesquioxane, Reactive and Functional Polymers, 67 1148-1156.

Isayev, I. S. \& Kennedy, J. P. (2004) Amphiphilic membranes crosslinked and reinforced by POSS, Journal Polymer Science: Part A: Polymer Chemistry, 42 4337-4352.

Iyer, S. \& Schiraldi, D.A. (2007). Role of Specific Interactions and Solubility in the Reinforcement of Bisphenol A Polymers with Polyhedral Oligomeric Silsesquioxanes, Macromolecules 40 4942-4952. 
Khotimskii, K.V.; Filippova, V.G.; Bryantseva, I.S.; Bondar, V.I.; Shantarovich, V.P. \& Yampolskii, Y.P. (2000). Synthesis, transport and sorption properties and free volume of polystyrene derivatives containing Si and F Journal of Applied Polymer Science, 78 1612-1620.

Koh, K.; Sugiyama, S. \& Fukuda, T. (2005). Precision Synthesis of a Fluorinated Polyhedral Oligomeric Silsesquioxane-Terminated Polymer and Surface Characterization of Its Blend Film with Poly(methyl methacrylate), Macromolecules 38 1264-1270.

Krishnan, S. G. P \& He, C. (2005). Octa(maleimido phenyl) silsesquioxane copolymers. Journal Polymer Science: Part A: Polymer Chemistry, 43 2483-2494

Kudo, H.; Yamamoto, M.; Nishikubo, T. \& Moriya, O. (2006). Novel materials for large change in refractive index: synthesis and photochemical reaction of the ladder like poly(silsesquioxane) containing norbornadiene, azobenzene, and anthracene groups in the side chains, Macromolecules, 39 1759-1765.

Lee, Y.J.; kuo, S.W.; Huang, W.J.; Lee, H.W. \& Chang, F.C. (2004). Miscibility, specific interactions, and self-assembly behavior of phenolic/polyhedral oligomeric silsesquioxane hybrids, Journal Polymer Science: Part B: Polymer Physics, 42 11271136.

Li, Y.; Chung, T.S. \& Kulprathipanja, S. (2007). Novel $\mathrm{Ag}^{+}$-zeolite/polymer mixed matrix membranes with a high $\mathrm{CO}_{2} / \mathrm{CH}_{4}$ selectivity, AIChE Journal. 53610.

Lichtenhan, J. D.; Schwab, J. J.; Feher, F. J \& Soulivong, D. (1999). Method of functionalizing polycyclic silicones and the resulting compounds, U.S. Pat 5942638.

Lichtenhan, J. D.; Schwab, J. J. \& Reinerth, W. A. (2001) Nanostructured chemicals: A new era in chemical technology, Chemical Innovation, 31 3-5.

Liu, H. \& Zheng, S. (2005). Polyurethane Networks Nanoreinforced by Polyhedral Oligomeric Silsesquioxane, Macromolecular Rapid Communications, 26 196-200.

Li, H.; Zhang, J.; Xu, R. \& Yu, D. (2006). Direct Synthesis and characterization of crosslinked polysiloxanes via anionic ring-opening copolymerization with octaisobutylpolyhedral oligomeric silsesquioxane and octamethylcyclotetrasiloxane, Journal of Applied Polymer Science, 102 3848-3856.

Lin, H.Q. \& Freeman, B.D. http://www.netl.doe.govl/publications/proceedings/03/ ucrhbcu/Freeman.pdf.

Liu, Y.; Ni, Y. \& Zheng, S. (2006). Polyurethane Networks Modified with Octa(propylglycidyl ether) Polyhedral Oligomeric Silsesquioxane, Macromolecular Chemistry and Physics 207 1842-1851.

Liu, Y. \& Zheng, S. (2006). Inorganic-organic nanocomposites of polybenzoxazine with octa(propylglycidyl ether) polyhedral oligomeric silsesquioxane ${ }_{\llcorner}$Journal Polymer Science: Part A: Polymer Chemistry, 44 1168-1181.

Madhavan, K. \& Reddy, B.S.R. (2006). Poly(dimethylsiloxane-urethane) membranes: effect of hard segment in urethane on gas transport properties, Journal of Membrane Science, 283 357-365.

Madhavan, K. \& Reddy, B.S.R. (2009). Synthesis and Characterization of Polyurethane Hybrids: Influence of the Polydimethylsiloxane Linear Chain and Silsesquioxane Cubic Structure on the Thermal and Mechanical Properties of Polyurethane Hybrids, Journal of Applied Polymer Science, 113 4052-4065. 
Madhavan, K.; Gnanasekaran, D. \& Reddy B.S.R. (2009). Synthesis and Characterization of Poly(dimethylsiloxaneurethane) Nanocomposites: Effect of (In)Completely Condensed Silsesquioxanes on Thermal, Morphological, and Mechanical Properties, Journal of Applied Polymer Science, 114 3659-3667.

Madhavan, K. \& Reddy B.S.R. (2009). Structure-gas transport property relationships of poly(dimethylsiloxane-urethane) nanocomposite membranes, Journal of Membrane Science 342 291-299.

Maxwell, C. (1873). Treatise on Electricity and Magnetism, vol. 1, Oxford University Press, London.

Moaddeb, M. \& Koros, W.J. (1997). Gas transport properties of thin polymer membranes in the presence of silicon dioxide particles, Journal of Membrane Science, 125 143163.

Moreau, J. E. E.; Pichon, B. P.; Chi Man, M. W.; Bied, C.; Pritzkow, H.; Bantignies, J. L.; Dieudonn, P. \& Sauvajol, J. L. (2004). A Better understanding of the selfstructuration of bridged silsesquioxanes, Angewandte Chemie International Edition, 43 $203-206$.

Neumann, D.; Fisher, M.; Tran, L. \& Matisons, J. G. (2002). Synthesis and Characterization of an Isocyanate Functionalized Polyhedral Oligosilsesquioxane and the Subsequent Formation of an Organic-Inorganic Hybrid PolyurethaneJournal of American Chemical Society, 124 13998-13999.

Ni, Y. \& Zheng, S. (2004). A Novel photocrosslinkable polyhedral oligomeric silsesquioxane and its nanocomposites with poly(vinyl cinnamate), Chemistry of Materials, 16 51415148

Nunes, S.P.; Peinemann, K.V.; Ohlrogge, K.; Alpers, A.; Keller, M. \& Pires, A.T.N. (1999). Membranes of poly(ether-imide) and nanodispersed silica, Journal of Membrane Science, 157 219-226.

Oaten, M. \& Choudhury, N. M. (2005). Silsesquioxane-Urethane Hybrid for Thin Film Applications, Macromolecules 38 6392-6401.

Park, H.B.; Kim, J.K.; Nam, S.Y. \& Lee, K.M. (2003). Imide-siloxane block copolymer/silica hybrid membranes: preparation, characterization and gas separation properties, Journal of Membrane Science, 220 59-73.

Patel, N.P.; Miller, A.C. \& Spontak, R.J. (2003). Highly CO2-permeable and selective polymer nanocomposite membranes, Advanced Materials. 15 729-733.

Paul, D.R. \& Yampol'skii, Y.P. (1994). Polymeric Gas Separation Membranes, CRC Press, Boca Raton, FL.

Phillips, S. H.; Haddad, T. S. \& Tomczak, S. J. (2004). Developments in nanoscience: Polyhedral oligomeric silsesquioxane (POSS)-polymers, Current Opinion SolidState Materials Science, 8 21-29.

Rios-Dominguez, H.; Ruiz-Trevino, F.A.; Contreras-Reyes, R. \& Gonzalez-Montiel, A. (2006). Syntheses and evaluation of gas transport properties in polystyrene-POSS membranes, Journal of Membrane Science, 271 94-100.

Sheth, J.P; Aneja, A.; Wilkes, G.L.; Yilgor, E.; Atilla, G.E.; Yilgor, I. \& Beyer, F.L. (2004) Influence of system variables on the morphological and dynamic mechanical 
behavior of polydimethylsiloxane based segmented polyurethane and polyurea copolymers: a comparative perspective, Polymer 45 6919-6932.

Soh, M.S.; Yap, A.U.J \& Sellinger, A. (2007). Methacrylate and epoxy functionalized nanocomposites based on silsesquioxane cores for use in dental applications, European Polymer Journal, 43 315-327.

Table-Mohammadi, A. (1999). A review of the application of membrane separation technology in natural gas treatment, Separation and Purification Technology. 34 20952111.

Vu, D.Q.; Koros, W.J \& Miller, S.J. (2003). Mixed matrixmembranes using carbon molecular sieves. I. Preparation and experimental results, Journal of Membrane Science, 211 311334.

Wang, L. F.; Ji, Q.; Glass, T. E.; Ward, T. C.; McGrath, J. E.; Muggli, M.; Burns, G. \& Sorathia, U. (2000).Polymer 41 5083-5093.

Wara, N.M.; Francis, L.F. \& Velamakanni, B.V. (1995). Addition of alumina to cellulose acetate membranes, Journal of Membrane Science, 104 43-49.

Yang, J.M.; Lin, H.T. \& Lai, W.C. (2002). Properties of modified hydroxyl-terminated polybutadiene based polyurethane membrane, Journal of Membrane Science, 208 105117.

Yave, W.; Peinemann, K.V.; Shishatskiy, S.; Khotimskiy, V.; Chirkova, M.; Matson, S.; Litvinova, N. \& Lecerf, N. (2007). Synthesis, characterization, and membrane properties of poly(1-trimethylgermyl-1-propyne) and its nanocomposite with $\mathrm{TiO}_{2}$, Macromolecules, 40 8991-8998.

Yeganeh, H. \& Shamekhi, M. A. (2004). Poly(urethane-imide-imide), a new generation of thermoplastic polyurethane elastomers with enhanced thermal stability, Polymer 45 359-365.

Yeh, J.T. \& Pennline, H.W. (2001). Study of $\mathrm{CO}_{2}$ absorption and desorption in a packed column, Energy Fuels 15274.

Yoshino, M.; Ito, K.; Kita, H. \& Ich, K. (2000). Okamoto, Effects of hard-segment polymers on $\mathrm{CO} 2 / \mathrm{N} 2$ gas-separation properties of poly(ethylene oxide)-segmented copolymers, Journal Polymer Science: Part B: Polymer Physics, 38 1707-1715.

Youngblood, J.P. \& McCarthy, T.J. Ultrahydrophobic Polymer Surfaces Prepared by Simultaneous Ablation of Polypropylene and Sputtering of Poly(tetrafluoroethylene) Using Radio Frequency Plasma, (1999). Macromolecules 32 6800-6806.

Zeng, K. \& Zheng, S. (2007). Nanostructures and Surface Dewettability of Epoxy Thermosets Containing Hepta(3,3,3-trifluoropropyl) Polyhedral Oligomeric SilsesquioxaneCapped Poly(ethylene Oxide) Journal Physical Chemistry B 111 13919-13928.

Zhang, W.; Fang, B.; Walther, A. \& Muller, A.H.E. (2009). Synthesis via RAFT Polymerization of Tadpole-Shaped Organic/Inorganic Hybrid Poly(acrylic acid) Containing Polyhedral Oligomeric Silsesquioxane (POSS) and Their Self-assembly in Water, Macromolecules, 42 2563-2569.

Zhang, Y.; Lee, S.; Yoonessi, M.; Liang, K. \& Pittman, C. U.( 2006). Phenolic resintrisilanolphenyl polyhedral oligomeric silsesquioxane (POSS) hybrid nanocomposites: Structure and properties, Polymer, 47 2984-2996. 
Zheng, L.; Farris, R.J. \& Coughlin, E.B. (2001). Synthesis of polyethylene hybrid copolymers containing polyhedral oligomeric silsesquioxane prepared with ring-opening metathesis copolymerization, Journal Polymer Science: Part A: Polymer Chemistry, 39 2920-2928.

Zheng, J.; Ozisik, R.; Siegel, R. W. (2005). Disruption of self-assembly and altered mechanical behavior in polyurethane/zinc oxide nanocomposites, Polymer 46 10873-10882. 


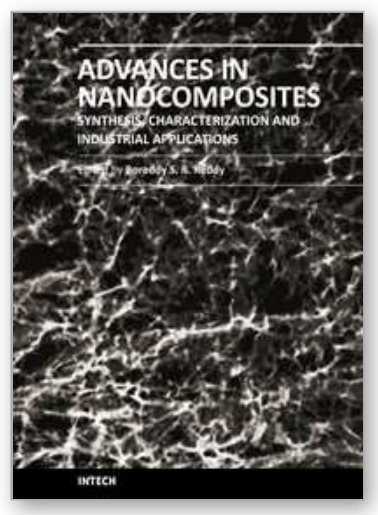

\author{
Advances in Nanocomposites - Synthesis, Characterization and \\ Industrial Applications
}

Edited by Dr. Boreddy Reddy

ISBN 978-953-307-165-7

Hard cover, 966 pages

Publisher InTech

Published online 19, April, 2011

Published in print edition April, 2011

Advances in Nanocomposites - Synthesis, Characterization and Industrial Applications was conceived as a comprehensive reference volume on various aspects of functional nanocomposites for engineering technologies. The term functional nanocomposites signifies a wide area of polymer/material science and engineering, involving the design, synthesis and study of nanocomposites of increasing structural sophistication and complexity useful for a wide range of chemical, physicochemical and biological/biomedical processes. "Emerging technologies" are also broadly understood to include new technological developments, beginning at the forefront of conventional industrial practices and extending into anticipated and speculative industries of the future. The scope of the present book on nanocomposites and applications extends far beyond emerging technologies. This book presents 40 chapters organized in four parts systematically providing a wealth of new ideas in design, synthesis and study of sophisticated nanocomposite structures.

\title{
How to reference
}

In order to correctly reference this scholarly work, feel free to copy and paste the following:

Boreddy S. R. Reddy and D. Gnanasekaran (2011). Structure-Gas Transport Property Relationships of Poly(dimethylsiloxane-urethane) Nanocomposite Membranes, Advances in Nanocomposites - Synthesis, Characterization and Industrial Applications, Dr. Boreddy Reddy (Ed.), ISBN: 978-953-307-165-7, InTech, Available from: http://www.intechopen.com/books/advances-in-nanocomposites-synthesis-characterizationand-industrial-applications/structure-gas-transport-property-relationships-of-poly-dimethylsiloxane-urethanenanocomposite-membr

\section{INTECH}

open science | open minds

\section{InTech Europe}

University Campus STeP Ri

Slavka Krautzeka 83/A

51000 Rijeka, Croatia

Phone: +385 (51) 770447

Fax: +385 (51) 686166

www.intechopen.com

\section{InTech China}

Unit 405, Office Block, Hotel Equatorial Shanghai

No.65, Yan An Road (West), Shanghai, 200040, China 中国上海市延安西路65号上海国际贵都大饭店办公楼 405 单元

Phone: +86-21-62489820

Fax: $+86-21-62489821$ 
(C) 2011 The Author(s). Licensee IntechOpen. This chapter is distributed under the terms of the Creative Commons Attribution-NonCommercialShareAlike-3.0 License, which permits use, distribution and reproduction for non-commercial purposes, provided the original is properly cited and derivative works building on this content are distributed under the same license. 